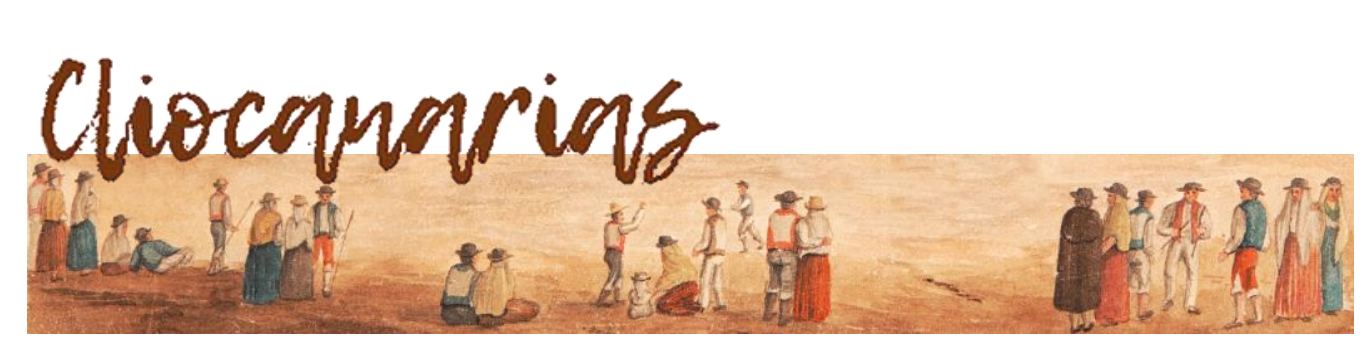

ISSN 2695-4494

https: / / doi.org/ 10.53335/cliocanarias.2021.3.02

\title{
LOS VEGUEROS CANARIOS EN CUBA DURANTE EL SIGLO XVIII
}

\author{
THE CANARIAN VEGUEROS IN CUBA DURING THE $18 T H$ CENTURY
}

\section{Julio Alberto DOMÍNGUEZ EXPÓSITO*}

RESUmen: El desarrollo tabacalero de la isla de Cuba, sumado al constante flujo de emigrantes canarios durante siglos, fueron factores influyentes en el devenir político, comercial, social y cultural de la isla. La fusión de las dos realidades, tabaco y emigrante isleño, crearon a lo largo de la historia cubana la mítica figura del cultivador de tabaco, conocido como veguero. Este artículo pretende arrojar luz sobre la vida de dicho personaje, que unido a la visión del labrador y del guajiro, formará parte del imaginario colectivo cubano.

Palabras Clave: Canarias, Cuba, emigrante, monopolio, tabaco, vegueros.

ABSTRACT: Tobacco development in Cuba, combined with the Canarian migrant movements for centuries, were important factors of the politics, business, society and culture in the island. Fusion of two realities, tobacco and canary emigrant made the mythical figure of the tobacco farmer, who was known as veguero along the cuban history. This article wants to shed light on the subject, who together with the vision of "labrador" and "guajiro", will be part of the Cuban collective imaginary.

KEYWORDS: Canarias, Cuba, emigrant, monopoly, tobbaco, vegueros.

\section{Introducción}

A lo largo de la historia, el pueblo canario siempre ha destacado por ser protagonista en los acontecimientos históricos de muchos territorios que forman parte del continente americano. Este hecho se debe a la condición de pueblo emigrante que los canarios siempre han ostentado a lo largo del tiempo. La posición del archipiélago como zona de paso y escala para muchas

* Graduado en Historia. C. e.: juliodominguezexposito@gmail.com 
naves que tenían como destino el Nuevo Mundo, sumada a los factores históricos que provocaron la decadencia de diferentes ciclos económicos, desencadenó esa relación entre el canario y su devenir emigrante, algo que aún perdura en la mente y en la cultura de los isleños.

Esta peculiaridad estuvo relacionada con el proceso migratorio que se inició en Cuba desde los principios de su colonización en el siglo XVI. La isla comenzaba a experimentar un crecimiento paulatino gracias a una serie de cultivos como el tabaco o el azúcar. Especialmente, durante el siglo XVII y sobre todo el s. XVIII, el cultivo tabacalero se desarrolló de tal manera que se convirtió en uno de los negocios más rentables e influyentes en la "perla antillana".

Pero a medida que crecía el comercio y el cultivo en la isla, comenzaban a observarse las carencias que provocaban una ralentización del proceso. La falta de población, tanto de mano de obra como de componente humano para colonizar la isla, era un problema que la Corona tuvo que solucionar. Lo pudo conseguir gracias a la migración, especialmente con aquella que llegaba progresivamente desde el archipiélago canario. Aquellos que llegaron a la isla caribeña se asentaron en los territorios que eran claves para las políticas de colonización de la monarquía, cuya misión era defender la isla de la expansión de potencias extranjeras. Pero sobre todo, esta migración fue la responsable de la creación de nuevas zonas de explotación agrícola.

Los "isleños", nombre que se les dio en la isla a los inmigrantes canarios, fueron la mano de obra que dominó dentro de las explotaciones de tabaco. Una figura de corte familiar, que trasladará este esquema de organización unifamiliar y patriarcal desde el hogar al propio cultivo. Será durante el siglo XVIII su máximo período de desarrollo, momento en el que los vegueros se verán envueltos en luchas rebeldes contra las normativas de aquellas autoridades comerciales que monopolizaban la producción y el comercio del tabaco dentro del reino de España. Del mismo modo, los vegueros canarios fundarán muchas de las comunidades que actualmente siguen existiendo, dejando una herencia cultural en la isla que ha llegado hasta nuestros dias.

Finalmente, este tipo de explotación sufrirá un retroceso, fruto del crecimiento de otro sistema de producción: la plantación, relacionado con el cultivo de la caña de azúcar y en menor medida del café. Sin embargo, la decadencia del cultivo tabacalero no supondrá la desaparición total del veguero, pues su legado perdurará a lo largo del tiempo gracias a la seña de identidad que dejó en Cuba, la cual tiene cierto "acento canario", algo que une fraternalmente a la isla antillana con el archipiélago canario.

El objetivo de esta exposición es analizar la huella que dejó el veguero canario en Cuba. Partimos, con base en estudios previos, de una observación sobre las consecuencias económicas, sociales y culturales que provocó la llegada de los "isleños" a Cuba y, en especial, aquellas que se desplegaron en las vegas tabacaleras explotadas por canarios.

Algo que también debemos tener en cuenta sobre los diferentes estudios sobre este tema es el estado de la cuestión en la historiografia. El enfoque teórico es oportuno orientarlo en la dirección relacionada con el fenómeno migratorio canario en Cuba y en torno al sistema económico imperante en la isla. 
Estas dos realidades crearon un fenómeno social que contribuyó, entre otras cosas, a crear la figura del campesino cubano conocido como "guajiro".

La consulta historiográfica depara, por un lado, diversos trabajos en los que se realiza un análisis de las diferentes conexiones migratorias que tuvieron lugar entre la isla antillana y el archipiélago canario. Por otro, el ámbito comercial que impulsó este fenómeno ha suscitado un exhaustivo estudio de las conexiones mercantiles, no solo las creadas debido al tabaco, sino a otros productos y manufacturas que fluian dentro de las rutas comerciales. Pero, sobre todo, los sucesos de las revueltas vegueras fueron los que han tenido una gran repercusión histórica y han sido objeto de estudio de muchos especialistas en el tema. Sin embargo, dentro de la revisión historiográfica efectuada apenas hemos hallado referencias sobre esta temática desde un enfoque del género, debido quizás a una cierta carencia de datos históricos disponibles.

Se trata, en definitiva, de que esta aportación divulgativa sirva a modo de sintesis aclaratoria de los hechos acaecidos en Cuba durante el siglo XVIII, y que a la vez pueda tener utilidad para aquellos lectores interesados en el tema.

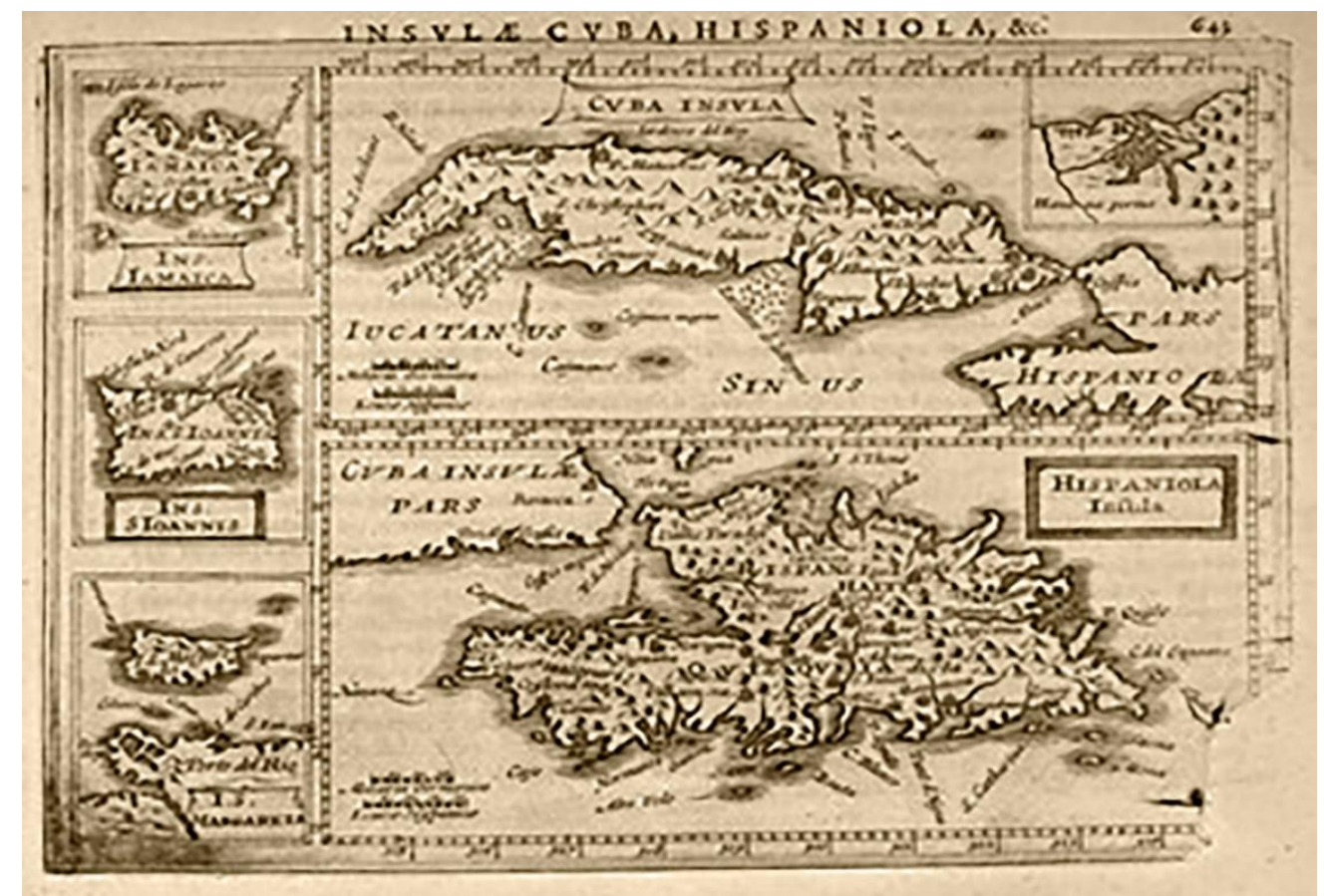

[1] En la parte superior, isla de Cuba en el "Atlas minor Gerardi Mercatoris". MERCATOR, G. (1512 -1594): Amsterodami Ex Officina Ioannis Ianssonii, 1634. Fuente: Flickr, Fondo Antiguo de la Biblioteca de la Universidad de Sevilla.

\section{Emigración canaria a Cuba durante la Edad Moderna. Destino de los isleños durante siglos}

El movimiento migratorio, tanto individual como colectivo, a larga distancia, se produce en el archipiélago canario desde su redescubrimiento y conquista por las potencias europeas, a partir de los albores del siglo XV. Según Bruquetas de Castro, en un primer momento se desarrolló una emigración entre islas 
que, tras la llegada castellana al continente americano, cruzó el Atlántico. Durante la Edad Moderna, la emigración hacia América tendrá gran relevancia a causa de la magnitud que alcanzó gracias una serie de factores ${ }^{1}$.

\subsection{Primera etapa de poblamiento}

El 27 de octubre de 1492 arribaron por primera vez, al mando de Cristóbal Colón, los primeros navíos a la isla de Cuba. Se iniciaba así la colonización de la isla antillana dentro de lo que se conoce como la era de los descubrimientos y conquistas, comenzando este cambio a partir de la primera mitad del siglo $\mathrm{XV}$, permitiendo a la sociedad europea expandirse y entrar en la Edad Moderna ${ }^{2}$.

De todos los territorios de América, fue Cuba uno de los que acogió más número de emigrantes en virtud de su prosperidad económica y la buena disposición de las autoridades para la inmigración. La investigación de Rodríguez Mendoza, plasmada en su tesis doctoral, afirma que a los pocos años de la conquista Cuba se convierte en una importante escala en el tráfico marítimo entre la metrópoli y el Nuevo Mundo. Sin embargo, su despoblación era un hecho evidente. La casi desaparición indigena, sumada a la atracción que ejercían sobre los colonos europeos las minas de plata mexicanas y andinas, además de las de oro de Colombia, estaba dejando a la isla sin habitantes. La mayoría de la emigración española tenía otros destinos como México, Perú y Colombia.

A pesar de que los canarios ya se habian introducido en Cuba desde principios del siglo XVI, su número debió ser pequeño. Estos habían desembarcado en la isla para labores de operarios en los primeros ingenios azucareros; otros tantos se instalarian a partir de las incursiones mercantiles. Durante este período también podemos encontrar a algunos inversores en la instalación de trapiches en las cercanias de La Habana ${ }^{3}$.

La despoblación de la isla no hizo que el puerto de La Habana perdiera protagonismo, ya que era el lugar de concentración de las flotas que, saliendo de Sevilla, tocaban en los grandes puntos mercantiles ligados a las exportaciones de metales americanos: Veracruz, Cartagena de Indias y El Callao. Esto le confirió un cierto protagonismo y la condición de un influyente mercado. No obstante, paulatina decadencia del comercio entre España y América era cada vez más clara a partir de 1610, lo que ocasionó una mengua del tráfico en el extremo occidental de Cuba. Ahora bien, a medida que la llegada de las flotas se alargaba más en el tiempo, aumentaba la influencia de los mercantes isleños que traficaban con los puertos de la isla 4 .

Mientras avanzaba el siglo XVII, el crecimiento del comercio canario-cubano alcanzará gran intensidad, llegando incluso a superar con holgura al realizado

\footnotetext{
1 BRUQUETAS DE CASTRO, F.: "La emigración canaria a Cuba y El Caribe. Aspectos cualitativos", en XXIII Coloquio de Historia Canario-Americana, Gran Canaria, 2020, pp. 1-4.

2 RODRÍGUEZ MENDOZA, F.: La emigración del noroeste de Tenerife a América durante 17501830, (tesis doctoral), Tenerife, 2004, pp. 607-625.

${ }^{3}$ Ibid., pp. 607-625.

4 No solo con La Habana, sino también con el extremo oriental, el de Santiago, primera capital y sede del obispado, que había quedado al margen del tráfico comercial.
} 
con Sevilla. Según ocurre ese hecho, comienza a aumentar de forma constante el número de inmigrantes procedentes del archipiélago canario en la isla. Una parte se asentará en el extremo oriental, como complemento de familias blancas a las minas de El Cobre, donde se empleaba como norma básica el trabajo esclavo, o en la fundación de Camagüey, hasta el punto en que se integrarán entre la oligarquía local fundadora. Entre los inmigrantes de este momento encontramos al grancanario Silvestre de Balboa, primer poeta de Cuba, que trabajará como escribano en la localidad5.

\subsection{El período del "tributo de sangre"}

Tras un largo periodo de prosperidad, donde el crecimiento económico y demográfico estuvo al alza ${ }^{6}$, en la segunda mitad del siglo XVII la economía isleña mostraba señales manifiestas de crisis debido a varias causas, una de ellas la independencia de Portugal en 1640, que conllevó la pérdida del tráfico mercantil con sus colonias. Por este motivo, las clases dominantes en Canarias apostaron por una emigración americana para así seguir manteniendo sus concesiones mercantiles.

La ocupación de la isla de Jamaica en 1655 por Inglaterra y la expansión francesa en la isla de Santo Domingo desencadenó un cambio de estrategia por parte de la Corona hispánica. La oligarquía canaria vio la oportunidad de rentabilizar la situación, desarrollando una estrategia de vinculación y continuidad en la repoblación de las numerosas tierras deshabitadas en el área caribeña y, más adelante, en el Río de la Plata. Ante esta situación, en 1678 el monarca dictó una real cédula que vinculó la permisión de 100 toneladas en la exportación a cambio de la salida de cinco familias de cinco miembros, ligando desde entonces los intereses mercantiles de las clases dirigentes en Canarias a las politicas poblacionistas de la Corona.

Este fue el punto de partida de lo que se conocerá como "el tributo de sangre». La Corona limitó el comercio del archipiélago canario a las áreas menos pobladas y desarrolladas por aquel entonces, aunque también es cierto que tanto Cuba como Venezuela irán desarrollando un crecimiento mayor ${ }^{7}$.

En el caso de Cuba, observamos que la isla se convierte en uno de los grandes destinos de la migración canaria. A partir de la segunda mitad del siglo XVII, en La Habana y sus alrededores comenzará a desarrollarse en las vegas de sus ríos y arroyos próximos la expansión del cultivo del tabaco. Estas serán arrendadas por canarios que eran atraidos por las posibilidades que ofrecía el precio del tabaco cubano. La monarquía impulsará la fundación estratégica de pueblos como Matanzas, pero este cultivo crecerá en las cercanías de La Habana (surgen poblaciones como Jesús del Monte, en las cuales los canarios se instalarán y formarán núcleos familiares ${ }^{8}$ ) extendiéndose a la región central

\footnotetext{
${ }^{5}$ RODRÍGUEZ MENDOZA, F.: La emigración del noroeste de Tenerife..., op. cit., pp: 607-625.

${ }^{6}$ Nos referimos a la época de las mayores exportaciones de vino.

7 HERNÁNDEZ GONZÁLEZ, M.: "La emigración canaria a América a través de la historia", en Cuadernos Americanos, Tenerife, 2008, pp. 139 - 147.

$8 \quad \ldots 1^{\circ}$ - f. ${ }^{\circ} 135$ - Miércoles, tres de noviembre de mil seiscientos y ochenta y nueve en la hermita de Sor. San Cristóval [5], que está en Paso Seco, casamos y velamos a Baltasar López hijo de Juan López y María Pérez, naturales de la isla de Tenerife, y a Maria Hernández, hija
} 
o a Camagüey. Otras actividades que efectuarán los canarios en Cuba será el cultivo de maloja ${ }^{9}$ o de vegetales para la ciudad o para el ganado, así como el trabajo como mayorales. Y junto con una población dedicada al comercio, serán el conjunto de sus labores ${ }^{10}$.

Las élites mercantiles ganaron grandes sumas de dinero que usaron para mezclarse con la oligarquía cubana y para luchar por el control de la tierra. En lo referente a estas familias, como ejemplo encontramos el caso de la del canónigo Nicolás Estévez Borges, natural de Icod, que llegará a constituir ingenios azucareros de gran importancia y fortunas tan señaladas que le permitieron edificar en La Habana un hospital y donar a su pueblo de origen -Icod de los Vinos- una grandiosa cruz de plata de más de 47 kilos, tallada en filigrana. Sin embargo, la mayoría de los inmigrantes isleños eran humildes

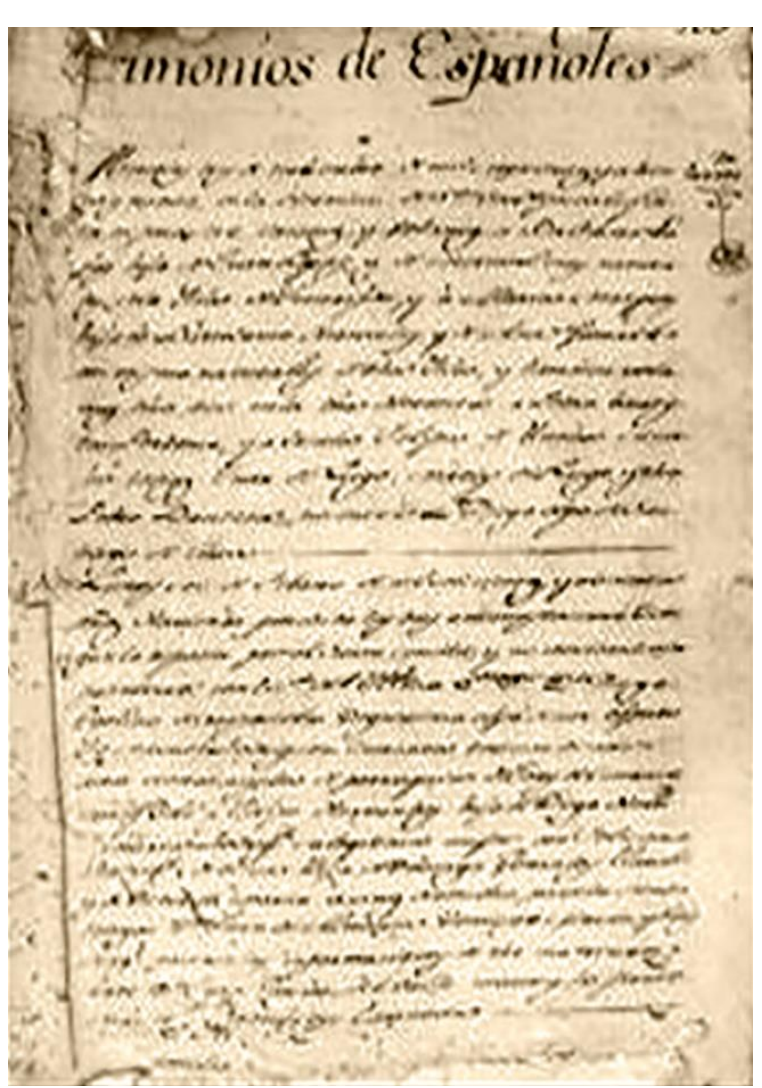
campesinos que en barrios rurales como de Jesús del Monte, Bejucal o la población de Santiago de las Vegas, así como en antiguas poblaciones de nativos como Guanabacoa, comenzaron el cultivo tabacalero, que aumentó su popularidad en el Viejo Mundo ${ }^{11}$. Significó el comienzo de estas poblaciones, en las que los vegueros jugaron un papel importante, pues triunfaron sobre los propietarios y consiguieron asentarse en tierras que, a través de mediaciones con la Corona después de diferentes pleitos, les fueron concedidas para su explotación ${ }^{12}$.

[2] Primer matrimonio de canarios en Jesús del Monte. Archivo Parroquial, Libro 1, sección de matrimonios de españoles, folio 135. Fuente: NUMA AGUILA, L: "Los canarios de Jesús del Monte...", art. cit.

\subsection{La llegada de canarios a Cuba durante el siglo XVIII}

El éxodo migratorio de los canarios continuó a lo largo del siglo XVIII y se trató de una situación continua y normalizada durante la centuria. El notable

de Bartolomé Hernández y de Ana González, asímismo naturales de dicha isla; y también velamos dicho día en la dicha hermita a Pedro Bautista Perdomo y a Úrsula Felipa de Llerena, su mujer. Testigos: Juan de Lugo, Matías de Lugo y dicho Pedro Bautista, presentes. Y lo firmé. Diego, Obpo. de Santiago de Cuva (NUMA AGUILA, L: "Los canarios de Jesús del Monte, mitos y realidades", en La gaveta de Aguere, La Laguna, 2014. [Recurso en linea: <http://lagavetadeaguere.blogspot.com/2014/07/los-canarios-de-jesus-del-monte-mitos-y.html].

${ }_{9}$ Alimento para el ganado.

10 HERNÁNDEZ GONZÁLEZ, M.: "La emigración canaria...", art. cit., pp. 139-147.

${ }^{11}$ RODRÍGUEZ MENDOZA, F.: La emigración del noroeste de Tenerife..., op. cit., pp. 607-625.

12 HERNÁNDEZ GONZÁLEZ, M.: "La emigración canaria...», art. cit., pp. 139-147. 
crecimiento demográfico, la falta de tierras, las dificultades exportadoras, las carencias en el abastecimiento... incitaban a la población a salir de forma legal o clandestina en los navíos que iban a Indias. Sin duda alguna, la emigración canaria hacia América fue una respuesta para dar solución a los problemas y necesidades de entonces.

Durante la segunda mitad del siglo XVIII comenzó la reglamentación del libre comercio; sin embargo, en un primer momento solo se autorizó el tráfico directo entre puertos americanos y peninsulares, e igualmente el tráfico interprovincial en América. Además, se suprimió la Casa de Contratación, lo que supuso una mayor flexibilidad administrativa para la navegación. En el caso de Canarias, la repercusión que tuvieron estas nuevas politicas no fue positiva, ya que dañará al comercio exportador canario, convirtiéndose la emigración en una especie de alternativa al tráfico de mercancías.

También prosiguió la emigración apoyada y controlada por la Corona para contrarrestar la influencia de potencias extranjeras, pero fueron los casos de Caracas y La Habana los que atrajeron a una mayor cantidad de canarios. Se produjeron entonces importantes embarques de familias isleñas, algo que está relacionado con la geoestrategia que desplegó España en América para mantener el control de sus colonias. En relación con este asunto encontramos las expediciones que salieron desde Canarias con destino a Luisiana para llevar a cabo su poblamiento.

La corriente migratoria de esta coyuntura estuvo favorecida, en primer lugar, por la Junta de Fomento de La Habana, y posteriormente por la Real Sociedad Económica de Amigos del País. A esto se añadió el deseo de blanquear la raza y la guerra social que se desató en Venezuela, lo que favoreció que los canarios que iban a América en busca de fortuna orientaran su destino hacia Cuba, proceso que fomentó la población de este territorio con canarios de familias poco pudientes. En ese sentido, mencionemos el caso de 75 familias de isleños (375 personas) que viajaban con destino a La Florida en 1758. Este tipo de viajes influyeron directamente en el aumento de la población de Cuba, debido a que muchas familias que emigraron desde Canarias promovidas por la Real Compañía de La Habana - a la que nos referiremos más adelante- desertaron en su escala habanera y se internaron en la isla. Con la cesión de Florida durante este periodo, la gran mayoría de ellos se estableció en el occidente cubano ${ }^{13}$.

Es importante señalar que, a medida que crecía de forma considerable la emigración, se hacian menos rentables los productos canarios (aguardiente y vinos), aunque es un fenómeno anterior al libre comercio. La introducción de este entre 1765 y 1778 redundó notablemente en la exportación de productos canarios y extranjeros. Los primeros años de su puesta en funcionamiento parecen de una cierta bonanza y de fuertes inversiones en riesgos, siendo La Habana un destino tradicional de las corrientes migratorias canarias. Gene-

${ }^{13}$ RODRÍGUEZ MENDOZA, F.: La emigración del noroeste de Tenerife..., op. cit., pp. 7-15. 
ralmente, no se viajaba con intención de establecerse, sino de realizar actividades comerciales que en pocos años obtuviesen un capital de cierta consideración que les permitiera afianzarse social y económicamente en las islas ${ }^{14}$.

Manuel Hernández ha expuesto ${ }^{15}$ que el proceso migratorio se reforzó en las décadas que sucedieron a 1770 como resultado de la decadencia general del comercio canario-americano, llevando a los capitanes y dueños de embarcaciones a dedicarse preferentemente a la emigración. El cambio cualitativo aconteció en 1772, con el libre comercio que las islas disfrutaron hacia el área caribeña, con excepción del puerto de La Guaira. La emigración hacia La Habana fue favorecida por ser destino principal del libre comercio.

Con la declaración de guerra contra Inglaterra en 1779, en el marco de la Guerra de la Trece Colonias, el comercio canario-americano experimentó una época de total estancamiento y paralización y, como consecuencia de ello, la emigración quedó interrumpida. Con la paz se constata un cierto relanzamiento económico en los viajes a América, especialmente con la emigración durante el período entre 1783 y $1793^{16}$.

En esta década predominaron los buques con destino a La Habana gracias a las expectativas de crecimiento económico cubano. También influyó la generalización del libre comercio, que trajo consigo consecuencias directas como la transformación en el intercambio de mercancías, con el cambio de manufacturas extranjeras y personas. Esto es algo que preocupó a las clases dominantes agrarias, pues cada vez era menos la cantidad de productos que podian enviarse a América (vinos o aguardientes), de modo que el control del comercio pasó a manos de comerciantes que remitían barcos de pasajeros y manufacturas exportadas desde Europa.

Este espectacular aumento de la emigración llegó a su punto culminante en 1790, con el incremento del envío de milicias desde Santa Cruz de Tenerife, algo que motivó la respuesta del Cabildo insular con el fin de controlar las salidas de emigrantes para así evitar un vertiginoso despoblamiento de la isla. Sin embargo, las medidas que pretendian limitar el número de emigrantes fueron ineficaces, ya que quedaron en papel mojado. Es más, será en años posteriores cuando se acreciente la emigración de mujeres e hijos debido al empeoramiento de la situación económica del archipiélago ${ }^{17}$.

El final del siglo ilustrado y los comienzos de la centuria decimonónica se caracterizaron por ser una etapa en la que las guerras revolucionarias francesas y el proceso de independencia americano debilitaron drásticamente el tránsito migratorio hacia América. Esto se debió en gran medida a la reactivación de la economía canaria como consecuencia del espectacular aumento de las exportaciones vinícolas, motivadas por el bloqueo napoleónico durante el lapso comprendido entre 1796 y 1814. Sin embargo, a continuación aumentó la emigración a causa de la gran prosperidad azucarera en Cuba, inducida en parte por la desaparición de la competencia de azúcar en Haití. Durante las

\footnotetext{
14 Ibid., pp. $7-15$.

15 HERNÁNDEZ GONZÁLEZ, M.: La emigración canaria a América (1765-1824), Tenerife, 1999.

16 HERNÁNDEZ GONZÁLEZ, M.: "La emigración canaria...", art. cit., pp. 125 - 183.

17 RODRÍGUEZ MENDOZA, F.: La emigración del noroeste de Tenerife..., op. cit., pp. 607-625.
} 
luchas de independencia, la isla se mantuvo bajo el control español debido a la extraordinaria bonanza de su economía, algo que impulsó un auge en los procesos migratorios de la población canaria ${ }^{18}$.

\section{El tabaco y el isleño. La simbiosis que creó la figura del veguero}

Desde comienzo de la colonización de la isla, la inmigración isleña en Cuba había presentado características particulares. Manuel de Paz Sánchez nos relaciona ${ }^{19}$ su arraigo en el territorio de la campiña cubana, dejando de manifiesto su vocación claramente agrícola. Un gran número se concentró no solo en zonas de veguería tradicional ${ }^{20}$, sino también en zonas de plantación como Matanzas. Asimismo queda patente el elevado contingente femenino y su especial conexión e identificación con la realidad social cubana ${ }^{21}$.

\subsection{Nuevas poblaciones. El caso de la fundación de Santiago de las Vegas}

Como hemos visto con anterioridad, la migración de canarios que experimenta Cuba durante el apogeo tabacalero en el siglo XVIII trajo consigo el desarrollo y crecimiento de nuevos núcleos urbanos dentro del paisaje cubano, especialmente en aquellas tierras cercanas a las vegas de los ríos. El cultivo de la planta de tabaco en Cuba será uno de los mayores responsables de esta expansión demográfica.

Más adelante veremos cómo la monarquía española iniciará en la isla una politica proteccionista de apoyo al cultivo y comercio tabaquero. Se redactarán una serie de normas para mejorar estos aspectos, y del mismo modo se impulsará la creación de organismos relacionados con los beneficios del tabaco: la Real Compañía de Comercio de La Habana o la Real Factoría de Tabacos.

La labor tabacalera influirá en los cambios que se produjeron en el sistema de propiedad, configuración y tenencia de tierras, y del mismo modo afectará al aumento demográfico, además de fomentar la acumulación de capital comercial. Dentro de esta población, el papel de los inmigrantes canarios será determinante: "los isleños" ocuparán un pequeño espacio de tierra, en renta o propiedad, dedicándose al cultivo de tabaco. Estos canarios fueron tan determinantes para el desarrollo del cultivo del tabaco cubano que el propio veguero llegó a conocerse como «isleño".

Como dijimos al comienzo de este apartado, los canarios jugaron un papel destacado en la creación de nuevos núcleos poblacionales. Las propias vegas desarrollaron condiciones favorables para la creación y crecimiento de nuevos centros urbanos. Por ello en el siglo XVIII surgieron comunidades promovidas por grandes propietarios, como es el caso de San Felipe y Santiago o Santa María del Rosario, o bien por agricultores tabacaleros que contaron con el

\footnotetext{
18 Ibid., pp. $607-625$.

19 PAZ SÂNCHEZ, Manuel de: La imagen de sí mismos. Los isleños en la revista Islas Canarias de La Habana.

20 Ejemplo: Pinar del Río.

21 PAZ SÁNCHEZ, Manuel de: "La imagen de sí mismos. Los isleños en la revista Islas Canarias de La Habana", en Studia histórica. Historia Contemporánea, n. ${ }^{\circ} 15$ (1997), pp. 85-92.
} 
beneplácito real, como ocurrió con Santiago de las Vegas. Sobre esta última basaremos este apartado, apoyándonos en un artículo de Tornero Tinajero ${ }^{22}$.

Ya desde finales del siglo XVII se estableció una pequeña población veguera - la mayoria, arrendatarios - en las tierras del partido de Santiago. En 1744 dicha población decidió formalizarse como pueblo, hecho reflejado en el «Memorial" firmado por Miguel Macías, representante de las familias del lugar, en el que se pedía al gobernador de Cuba, Güimes y Horcasitas el permiso de fundación. En el documento se precisaban ciertos detalles del tamaño de la población, así como la imperiosa necesidad de que se les proporcionase tierra en propiedad.

Analizando algunos datos de las familias que solicitaron la creación del pueblo, sabemos que su dedicación agrícola se basaba en la cosecha del tabaco. También se deduce que la mayor parte de estos labradores eran arrendatarios que trabajaban una pequeña extensión de terreno. Es posible que contaran con esclavos, algo que choca con las afirmaciones de la historia tradicional, en las que se hace referencia al reducido porcentaje de mano de obra esclava utilizada en esa época. Conocemos el número poblacional: 309 personas; y de estas, se precisa en 81 sus lugares de procedencia: 37 canarios (6 de Gran Canaria, 1 de La Gomera, 1 de Lanzarote, 1 de La Palma, 1 de El Hierro y 26 de Tenerife), 35 del propio Santiago (aunque la mayoría eran de ascendencia canaria), 2 de Guanabacoa, 3 de La Habana, 3 de San Felipe y Santiago y 1 de Portugal. Esto demuestra la importante participación canaria en el proceso.

Las condiciones que el gobernador de Cuba exigía al proyecto eran dos: la primera, que los labradores solicitasen y buscasen una porción de tierra realenga; y segundo, que ellos mismos se ocuparan de la localización de dichas fincas para la creación de la ciudad. Finalmente, los vegueros eligieron un terreno situado a poca distancia de La Habana, así como de San Felipe y Santiago, cercano al puerto de Batabanó. Sin embargo, estas heredades parecian poseer propietarios. Los principales eran Dionisio de Berroa y Pedro Castellón, que argüían que dichos predios eran propiedad de sus antepasados desde 1600, cuando el Cabildo habanero se los había concedido. También el monasterio de Santa Catalina de Siena de La Habana poseía 23 caballerias en esos parajes. Pero el mayor propietario en el lugar era sin duda el marqués de San Felipe y Santiago, que habia adquirido la mayor parte de las tierras durante el siglo XVIII ${ }^{23}$.

A pesar de esto, los vegueros alegaban que sobre las mencionadas tierras podian erigir su población debido a que los supuestos dueños las detentaban, pues eran realengas, por lo que solamente tenian derecho de usufructo y no de propiedad. Los presuntos propietarios respondieron pronto a lo que consideraron una usurpación, presentando testimonios demostrativos de la legalidad de sus títulos. Omitiendo las diferentes declaraciones sobre la legitimidad de la posesión, los dueños albergaban motivos que no fueron reflejados en informe alguno. Especialmente, el marqués acerca de la cercana San Felipe y

22 TORNERO TINAJERO, Pablo: "Inmigrantes canarios en Cuba y cultivo tabacalero. La fundación de Santiago de las Vegas", en IV Coloquio de Historia Canario-Americana, 1980, pp, 507-529.

${ }^{23}$ Ibid. 
Santiago, en cuanto veía cómo la creación del nuevo núcleo podría restarle jurisdicción y súbditos, además de que la zona del futuro asentamiento la tenía destinada a la crianza de ganado. También existieron protestas de una serie de labradores canarios, dedicados al cultivo del tabaco, que temían que el nuevo emplazamiento les desposeyera de sus terrenos.

De esta manera, y debido a la disputa entre ambos bandos, la Corte finalmente acabó interviniendo con la real cédula de 26 de agosto de 1745, que autorizaba la fundación. Sin embargo, a pesar de las directrices que la Corona expuso en el texto, los vegueros siguieron encontrando trabas en el proceso. Los presuntos propietarios empezaron una serie de pleitos, y los vegueros no podian ocupar las tierras hasta su conclusión. Se volvió a precisar del rey para solucionar el problema, mediando este para que se entregasen las tierras a los labradores. Aun así, los isleños siguieron encontrando escollos, ya fuera en los trámites relativos a la medición de las tierras ${ }^{24}$, o en los embargos de sus productos para sufragar las rentas impagadas a los antiguos propietarios, creyendo que el monarca ya les había otorgado tierras en propiedad.

Ante estas dificultades, Miguel Macías se trasladó a la Corte para informar al rey sobre los acontecimientos, ordenando este al gobernador el cumplimiento de lo decretado, la devolución del dinero a los cultivadores y la ampliación del terreno concedido a 244 caballerías. Los vegueros al fin consiguieron asentarse en las tierras con toda la legalidad a su favor y se inició la institucionalización de la fundación: el 3 de mayo de 1749 se formó el primer Cabildo de la ciudad.

Cuando comenzó el reparto de tierras, tanto el gobernador como los supervisores se encargaron de que el reparto se realizase conforme a lo estipulado por la Corona para así conferirle la legalidad requerida. De esta forma quedaron repartidas 244 caballerias, que comprendian la ciudad y su entorno: 106 para otros tantos vegueros, 44 para la formación del pueblo, 14 para Miguel Macías, adjudicadas por orden de S. M., y 120 distribuidas en distintos vecinos, vendidos a censo y dedicados sus productos a propios de aquel Consejo 25 .

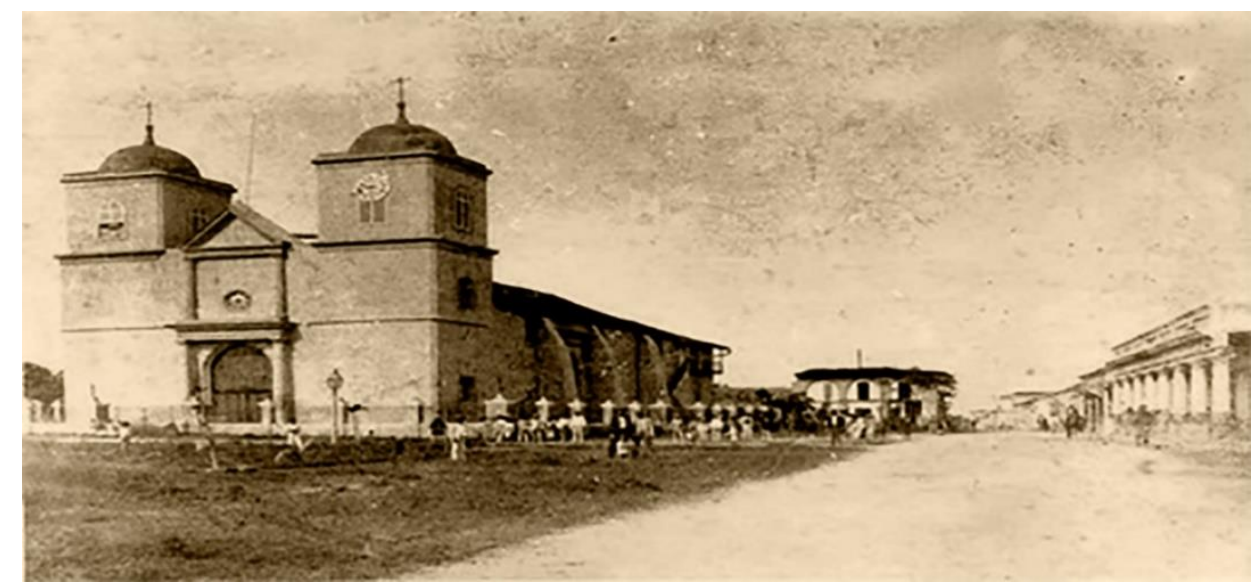

[3] La iglesia y plaza del Mercado de Santiago de las Vegas (1882). Fuente: Creative Commons.

${ }^{24} \mathrm{El}$ agrimensor nombrado para la medición se negó a su cometido, alegando que esas tierras tenían dueño.

25 TORNERO TINAJERO, Pablo: "Inmigrantes canarios en Cuba y cultivo tabacalero...", art. cit., pp. 507-529. 
En 1771 el teniente gobernador de La Habana, Pascual de Cisneros, reafirma la mencionada real cédula de 26 de agosto de 1745, que ordenaba fundar y establecer el pueblo de Santiago de las Vegas. A la vez, se argumentó la importancia de aumentar la población para mejorar el comercio y la agricultura del tabaco en la zona. Esto permite corroborar la importancia del producto tabacalero en el proceso de creación de la ciudad.

Pascual de Cisneros también nos informa de las principales características geográficas, urbanísticas y sociológicas del pueblo. Al norte lindaba con La Habana hasta el Río Calabazar; al sur, con el Surgidero del Batabanó; al este, con la villa de Guanabacoa; y al oeste, con la iglesia auxiliar del Quemado. Todas las calles presentaban un trazado a cordel: de norte a sur y de este a oeste, dividida la urbe en 64 manzanas, y estas en 8 solares. En el centro de la ciudad se ubicaba la plaza pública, y frente a uno de sus lados se alzaban las casas del Cabildo, que disponía de cárcel pública y dos aljibes. También el núcleo poblacional contaba con iglesia, hospital y cuartel 26 .

Durante este período, la población comprendía 204 casas y 680 personas, mientras la suma de vecinos de la ciudad y sus alrededores ascendia a 3.329. Según Cisneros, estaba dotada de panaderías, boticas, zapaterias, sastrerías, herrerías... La culminación del proceso de gestación de la localidad llegó con la real cédula de 24 de junio de 1755, que otorgó a Santiago de las Vegas el título de villa.

Finalmente, terminó la lucha entre los vegueros y grandes propietarios por el control de las tierras. Hay que destacar la ayuda de la Corona, ya que sin su intervención hubiese sido imposible para los isleños la creación de la población. Esta disposición real patentiza la preocupación regia de proteger los cultivos tabacaleros para mejorar así la producción de tabaco. Por ello la presencia tabacalera resulta primordial para comprender cómo los vegueros canarios tuvieron un significativo papel en la creación y desarrollo de nuevos núcleos poblacionales en $\mathrm{Cuba}^{27}$.

\subsection{El día a día. El arte del cultivo y cuidado de las plantas de tabaco}

Distintos trabajos ${ }^{28}$ relacionan al veguero con el cuidado de la planta de tabaco que cultivaba. La dedicación a dicho cultivo fue algo que distinguió a este agricultor, siendo una habilidad que tuvo su origen en su patria isleña. Fue una característica que aportó aún más a la mítica figura veguera encuadrada en el mundo rural cubano.

La imagen que desprende el veguero es la de un personaje que, a diferencia de la brutalidad y calamidad que ofrecía el trabajador de la plantación, tuvo un carácter independiente y de agricultor libre. Se ha conservado, gracias al relato escrito de aquellos que pudieron ser testigos, las técnicas y métodos de cultivo de los vegueros. Dichos testimonios describen cómo el veguero, arrancando ciertos brotes específicos de la planta, podía aumentar o disminuir su

26 TORNERO TINAJERO, P.: «Inmigrantes canarios en Cuba...», art. cit., pp. 507-529.

27 Ibid., pp. 507-529.

28 PAZ SÁNCHEZ, Manuel de, y Manuel HERNÁNDEZ GONZÁLEZ: La América Española (1763-1898). Cultura y vida cotidiana, Madrid, 2000. 
fortaleza o su crecimiento, o qué poda era necesaria llevar a cabo para así dejarle las hojas de mejor calidad. Pero, sobre todo, el cuidado más meticuloso que podía realizar un veguero - y que absorbía la mayor parte del tiempo de trabajo- se centraba en el exterminio de los insectos que eran agresivos con la planta.

En lo relativo a las características del terreno, los diferentes relatos y crónicas de los vegueros nos hablan de las mejores tierras para la práctica del cultivo tabacalero. Estas fincas o vegas se situaban en el suroeste de la isla, en la jurisdicción de Pinar del Río, en los márgenes del río o en terrenos bajos y húmedos, ocupando no más de una caballería ${ }^{29}$. La mitad del espacio se dedicaba también al cultivo del plátano y a "frutos menores"; es decir, la plantación estaba basada en un sistema que combinaba los productos de subsistencia con la producción de la rama de tabaco ${ }^{30}$.

Los edificios tradicionales que se enmarcan en la vega son las casas para la vivienda, otra para secar el tabaco y las cabañas denominadas bohíos, realizadas de forma primitiva y donde se cobijaban los trabajadores. El veguero, que no siempre era el dueño de la tierra, sino un simple arrendatario, residia en el lugar y dirigía personalmente las labores. Entre otros motivos, se debía a que el tabaco implicaba una dedicación exclusiva a su cultivo, ya que poseía una complejidad derivada de las condiciones naturales de producción y de los procesos de trabajo del tabaco. En consecuencia, la estrategia de producción más rentable fue la explotación basada en núcleos familiares, casi patriarcal, compuesta por varios hermanos que se rodeaban de allegados. Todo esto se encuadraba en un contexto de arrendamientos, en el que la aparcería constituía un sistema en el que se compartían gastos y riesgos.

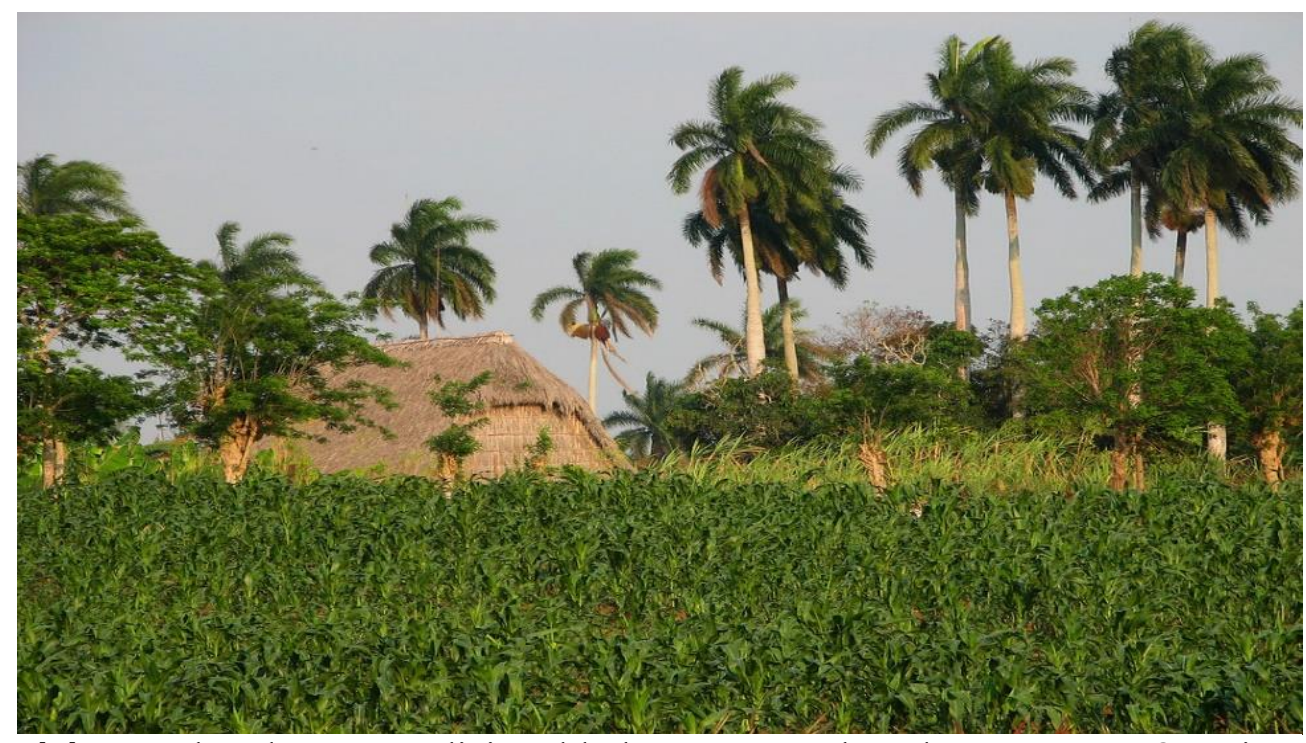

[4] Vega de tabaco y tradicional bohío en Vega de Palma. Fuente: Creative Commons.

${ }^{29}$ La caballería fue una medida de superficie utilizada por los españoles y sus colonias entre los siglos XV y XVIII, con unas medidas de 100 por 200 pies (30x61 m aproximadamente, o sea, unos $1.858 \mathrm{~m}^{2}$ ).

30 PAZ SÁNCHEZ, Manuel de, y Manuel HERNÁNDEZ GONZÁLEZ: La América Española (1763-1898)..., op. cit., pp. 183-190. 
El guajiro blanco, en el caso de disponer de suficientes tierras. empleaba "partidarios", en su mayoría isleños que podían ser parientes o vecinos originarios de su comarca migratoria de origen, conocedores del oficio de veguero en esa u otras explotaciones agrícolas. Estos se hospedarían en la explotación, viviendo allí a cambio de comida y del acuerdo establecido con el propietario.

El tabaco, tras su recolección y secado en las casas de tabaco, se agrupaba en gavillas, manojos y tercios, transportándose a lomos de bestias hasta el centro distribuidor: La Habana.

Estos procesos quedaron plasmados en los testimonios de viajeros, como fue el caso de Samuel Hazard, personaje americano aficionado a fumar, el cual relató la vida que giraba en torno al tabaco. Pero también describió costumbres propias del tabaco, como la de la candela, que según el propio Hazard la describió como un auténtico lujo entre fumadores: Generalmente es un platillo o vaso de plata, lleno de cenizas de madera, entre las cuales se mantienen encendidos uno o dos carbones; se presentan en las comidas como si se tratara de un obligado plato, generalmente después de las frutas. Tenia la utilidad de encender el tabaco, siendo su resultado más conveniente que el fósforo, de olor intenso y desagradable, a diferencia del aroma que desprendía el buen habano ${ }^{31}$.

\subsection{La herencia isleña. El legado cultural de los vegueros en Cuba}

Con el nuevo contingente poblacional también vino su estilo de vida. Según el historiador Jesús Guanche, la llegada de isleños trajo consigo la arribada de costumbres y hábitos propios de la población canaria, que transfirieron a la sociedad cubana ${ }^{32}$.

El importante aporte demográfico producido por la emigración fue clave en los siglos XVII y XVIII. Ese continuo desplazamiento marcó de manera clara el surgimiento de la figura del campesino blanco cubano. Es tan palpable la influencia canaria en la sociedad cubana y en el guajiro que muchos de los hábitos y costumbres de este personaje tienen un denso sedimento canario ${ }^{33}$. Este culminó en el siglo XVIII coincidiendo con el auge veguero, conformando las características del campesino blanco cultivador de tabaco. Por lo tanto, desde el punto de vista cualitativo y cuantitativo, la cultura que antecedió al campesino cubano (criollos, canarios y cierto componente africano en zonas rurales) fue esencialmente de origen canario ${ }^{34}$.

La inmigración isleña se puede apreciar durante este siglo en la estrecha relación veguero-isleño. Es dificil desvincular esa actividad agraria del trabajo realizado por los canarios, tanto como de otros factores culturales (el folclore o la lengua) que presentan una notable herencia procedente del archipiélago. Uno de los rasgos que pueden estar relacionados también con la expansión demográfica y cultural isleña es el alto porcentaje de emigración femenina. La

\footnotetext{
31 Ibid., pp. 183-190.

32 GUANCHE, J.: "Aportes canarios a la cultura campesina cubana", en Revista de la Biblioteca Nacional José Martí, 3. ${ }^{a}$ serie, $n .^{\circ}$ 26, La Habana, 1985, p. 51.

33 MARRERO, L.: Cuba: economia y sociedad, Tomo IX, La Habana, 1972, p. 166.

34 GUANCHE, J.: "Aportes canarios a la cultura...", art. cit., p. 51.
} 
gran abundancia de mujeres canarias pudo haber sido un factor de influencia e integración sociocultural.

Respecto a esto último, los contactos socioculturales que se establecerán con la comunidad de origen africano traerán consigo ritos y costumbres relativos al mundo del espiritismo y de la brujería. Entre estos se extenderá el mito de que las brujas eran de origen canario. Tal convicción puede estar relacionada con el sentimiento de culpabilidad del marido al abandonar a su mujer y mantener en Cuba relaciones extramatrimoniales con cubanas. Ligada a estas creencias también vendrán remedios caseros contra enfermedades, como el cardón para el paludismo, o la entrada de productos como el ajo $^{35}$.

Otro de los aspectos culturales asociados a la inmigración canaria es el culto religioso cristiano y la advocación mariana de la Virgen de la Candelaria. Juárez Martínez y Sánchez Álvarez han formulado en un artículo ${ }^{36}$ que dicha representación mariana aparece en Cuba - al igual que en Canarias - con el fin de sustituir anteriores deidades prehispánicas. Posteriormente, la Candelaria se localizará en la isla coincidiendo con el circuito de migración canaria en América. Pero un aspecto singular que la diferencia de Canarias es que la población nativa fue prácticamente exterminada, y en su lugar el contingente poblacional destinado al trabajo forzoso fue sustituido por población africana. De ahí que durante el siglo XVIII tuvieran lugar muchas "apariciones milagrosas" relacionadas con este segmento de la población, aunque nunca hubo intención de evangelizar a los esclavos. Aun así, los archivos parroquiales demuestran que en ciertas etapas (durante los levantamientos libertadores) la catequización de los esclavos constituyó una cuestión primordial, siendo un método de control del esclavo. Por esa razón se sucedian apariciones "prodigiosas" de representaciones religiosas, utilizadas para encubrir deidades propias afrocubanas, como Changó37.

Fue durante este período cuando efectivamente se propagó el culto a la Virgen de Candelaria, aunque en Cuba se sostiene que se fusionó con las divinidades como Oyá u Oshún, de ahí que en la iconografia de la Candelaria cubana siempre estén presentes los nueve colores que identificaban a Oyá. El proceso de sincretismo que realizó la Candelaria en Cuba fue diferente del ocurrido en Canarias, ya que en Cuba la devoción mariana sustituyó a una divinidad que ya se había sincretizado ${ }^{38}$. Pero cierto es que las divinidades celestes y relacionadas con la fertilidad representaron un mundo paralelo al del archipiélago canario $^{39}$.

\footnotetext{
35 JUÁREZ MARTÍNEZ, A., y G. SÁNCHEZ ÁLVAREZ: "La Candelaria: herencia cultural de Canarias en la ruta de la mar atlántica: España-Cuba-México", en XXII Coloquio de Historia Canaria-Americana, Las Palmas de Gran Canaria, 2017, pp. 1-12.

36 Ibid.

37 Ibid., pp. 553-564.

${ }^{38}$ Atabeira en Oyá; Oshhún Atabeira; o ambas deidades en Atabeira.

39 JUÁREZ MARTÍNEZ, A., y G. SÁNCHEZ ÁLVAREZ: "La Candelaria: herencia cultural...", art. cit., pp. 553-564.
} 
También, la herencia que Canarias dejó en Cuba llegó en cierto modo al archipiélago. Muchas de las costumbres difundidas por los vegueros que iniciaron la etapa de esplendor del cultivo del tabaco en el siglo XVIII cruzaron el mar para asentarse en las islas de origen de estos emigrantes. Nos referimos al caso concreto, estudiado por José L. Hernández Cruz, de emigrantes provenientes de la comarca de Las Breñas o zonas de El Paso, entre otras, los cuales trajeron los medios y las técnicas para el desarrollo del cultivo de tabaco en La Palma. Con esto se refleja un intercambio cultural de ida y vuelta, desarrollado en las relaciones trasatlánticas que establecieron el archipiélago canario y Cuba. Ambos lugares mantuvieron una conexión que con el paso del tiempo fue en aumento, pero tuvo importante relevancia en el siglo XVIII gracias al proceso migratorio y a la labor realizada por los canarios en tierras cubanas $^{40}$.

\section{El monopolio del tabaco en España y Cuba durante el siglo XVIII}

Desde que el consumo de tabaco se incorporó a los hábitos de los europeos en el siglo XVII ha sido una fuente de ingresos constante, tanto comerciales como fiscales. De ello se aprovecharon los gobiernos que, en primer lugar, utilizaron los monopolios de distribución y venta del producto tabacalero, así como una onerosa fiscalidad ${ }^{41}$.

En este entramado comercial y monopolista se encontraban los vegueros como el primer eslabón de una cadena que englobaba el comercio del tabaco dentro de la monarquía durante parte del siglo XVII y la centuria siguiente. Con objeto de clarificar este contexto se dedica un apartado al monopolio tabaquero, teniendo en cuenta su desarrollo como institución, así como los acontecimientos que se produjeron durante el proceso ${ }^{42}$.

\subsection{El surgimiento del monopolio tabacalero en los territorios de la Corona española}

Los comienzos de la comercialización del tabaco en España son muy difusos, y para comentarlo nos basamos en especial en un estudio de varios autores ${ }^{43}$. Existen diversos testimonios que señalan ya desde comienzos del siglo XVII el hábito tabaquero en la sociedad de la metrópoli y sus colonias. Es el caso del testimonio de un cronista sevillano, recopilado por Domínguez Ortiz, el cual hace referencia a una serie de sucesos en Sevilla, mencionándose: Comenzó a verse el tabaco, tomábanlo en humo negros bozales; o la datación ofrecida por Rivero Muñiz, reseñando que la primera vez que aparece escrita la palabra tabaco en unas de las actas del Ayuntamiento de La Habana es en

40 CRUZ HERNÁNDEZ, JOSÉ L.: «Proceso migratorio de la Villa de Mazo e inserción en la cultura del trabajo tabacalero cubano", en TUDELA GALVÁN A.: Canarios en Cuba. Una mirada desde la antropología, Tenerife, 1996, p. 47.

${ }^{41}$ BERGASA PERDOMO, Óscar: "La fiscalidad sobre el tabaco", en SOLBES FERRI, Sergio, Juan José LAFORET HERNÁNDEZ, y Santiago de LUXÁN MELÉNDEZ: El mercado del tabaco en España durante el siglo XVIII: fiscalidad y consumo, Gran Canaria, 2000, p. 17.

42 Ibid., p. 17

43 LUXÂN MELÉNDEZ, Santiago de; M. GÁRATE OJANGUREN; y José M. RODRÍGUEZ GORDILLO: Cuba-Canarias-Sevilla. El estanco español del tabaco y Las Antillas (1717-1817), Gran Canaria, 2012, pp. 51-91. 
1616. Sea como fuere, debemos entender que ya en el seiscientos el consumo se había extendido en la sociedad española, aunque ciertamente existian disparidades de una zona a otra: a comienzos de dicho siglo la parte meridional de la península ibérica era la zona donde más arraigado estaba. Esta usanza tuvo un notable impulso durante el primer tercio de dicho siglo, por lo que desde entonces las Cortes comenzaron a plantearse la implantación de un estanco en el conjunto de los territorios de la Corona. Fue entre los años 16321636 cuando la propuesta para estancar el tabaco tendría éxito. Estos planteamientos se gestaron en medio de la delicada situación hispana debido a los diferentes problemas económicos y políticos (Guerra de los Treinta Años, malas cosechas...). El monarca Felipe IV se vio obligado a "empeñar" todos los recursos hacendísticos para poder llevar a cabo el pago de múltiples cargas comprometidas por la negativa coyuntura de la monarquía.

Dentro de las diferentes estrategias recaudadoras el conde-duque de Olivares pidió un esfuerzo económico para solventar los gastos del período. Tras una serie de acuerdos, uno de los sistemas para que las ciudades pudieran satisfacer esta nueva aportación fue mediante la fiscalidad del tabaco, aunque la primera de las pagas fue un fracaso. No seria hasta el 16 de diciembre de 1636 cuando definitivamente se aceptaria este recurso, que garantizaba unos ingresos con los que avalar o acreditar el asiento que deberian contratar los mercaderes o financieros ${ }^{44}$.

La monarquía, conforme a la politica hacendística que imperaba de manera tradicional en Europa, impuso el sistema de arriendos para la gestión administrativa del estanco, por lo que la real cédula de 28 de diciembre de 1636 hacía a Antonio de Soria el primero de sus arrendadores. En ella se estipulaban los precios del tabaco, las garantías de abastecimiento, penas por infracciones cometidas, etc. ${ }^{45}$. Todo este entramado administrativo encontraría su centro neurálgico desde sus inicios en Sevilla, capital por entonces del comercio con América. Desde este puerto llegaban todas las variedades de tabaco del Nuevo Mundo, y fue aquí donde se situó el primer centro manufacturero: la fábrica de San Pedro ${ }^{46}$.

Desde estos primeros pasos, el estanco se fundamentó en tres pilares: el abastecimiento de su materia prima (exportada desde Indias, especialmente desde $\mathrm{Cuba}^{47}$ ), la gestión de las manufacturas sevillanas y una venta controlada por un régimen de exclusividad de las distintas labores tabacaleras. La implantación del estanco trajo consigo un incremento del fraude y del contrabando, debido al aumento de las tasas aduaneras impuestas por el tabaco y por las posibles formas de lucrarse.

Como hemos mencionado, el primer período del estanco estuvo regulado bajo la administración de arrendatarios (1636-1684). A lo largo de los dos tercios finales del siglo XVII, la característica más notable del sistema estancado fue el mantenimiento del régimen de arrendamientos. Tan solo en un

44 Ibid., pp. $51-91$.

45 Ibid., pp. $51-91$.

46 En estos primeros momentos, su actividad se concentraba en la elaboración de dos variedades de tabaco en polvo.

${ }^{47}$ La materia también procedía de otras islas antillanas, Brasil o Virginia. 
corto periodo de tres años, coincidiendo con el reinado del último Austria, Carlos II, entre 1684 y 1687, se ensayó una gestión directa que no llegó a consolidarse 48.

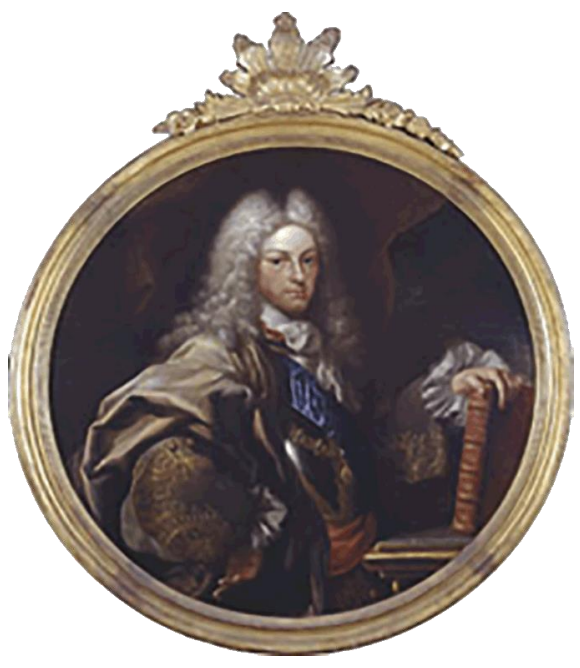

[5] MELÉNDEZ, Miguel Jacinto (1679-1734):

Felipe $V$ como protector de la Real Biblioteca Pública. Óleo sobre lienzo, 1727. Fuente: BNE.

Esta ocasión sí sería la última, ya que entre 1701 y 1704 concluiría el arrendamiento general con la llegada de la casa de los Borbones al trono de España de la mano de Felipe V. Con La real cédula de 9 de abril de 1701 se mandaba cesar los arriendos de tabaco en las 19 provincias castellanas para pasar a la administración por medio de empleados reales. Estas normas poco efecto surtieron en un principio debido al conflicto sucesorio. Por lo tanto, en 1704 tuvo que limitarse a la introducción de un administrador general dependiente de la Corona, junto a la administración directa de las provincias principales de Sevilla y Madrid, y admitiendo a la par el recurso del subarriendo de la renta en el resto de las demarcaciones. Debido a la Guerra de Sucesión, en los territorios de la Corona de Aragón la administración directa del estanco recayó en la Real Hacienda debido a los derechos de conquista, según los considerados "reinos rebeldes" iban rindiéndose: Valencia y Aragón en 1707, Cataluña en 1714 y Mallorca en 1715. Todos los territorios fueron adscritos como provincias semejantes a las castellanas, quedando englobadas en el régimen general de abastecimiento y distribución dependiente del administrador general.

El caso vasco-navarro tuvo la particularidad de que sus regimenes fiscales mantuvieron sus privilegios debido a la fidelidad mostrada a la Casa de Borbón durante las guerras dinásticas. Sin embargo, en cuanto este conflicto finalizó, entre 1716-1717, se estableció un acuerdo por el cual la hacienda foral conservaría los derechos relacionados con la propiedad teórica del estanco. Pero la Real Hacienda dispondrá de un control total de la gestión, quedando incorporado al estanco general como una administración provincial más. Pese a ello, las antiguas demarcaciones que se abolieron con la real orden de 1717 fueron repuestas en 1723, dejando al territorio vasco al margen del estanco. En el modelo navarro se mantuvo intacta la fórmula de arrendamiento.

Esta legislación se desenvolvió con cierta indefinición en el territorio español, manteniéndose vigente durante las primeras décadas del siglo XVIII, hasta la llegada de Patiño y el "partido español" en 1726. Ello significó el inicio de nuevas propuestas orientadas a la implantación de un sistema de gestión total, con una introducción en todos los niveles de la administración directa,

48 LUXÁN MELÉNDEZ, Santiago de, M. GÁRATE OJANGUREN, y José M. RODRÍGUEZ GORDILLO: Cuba-Canarias-Sevilla. El estanco español del tabaco..., op. cit., pp. 51-91. 
incluyendo la provincial. Los nuevos postulados verian la luz con la publicación del Decreto de Universal Administración de la renta de diciembre de 1730. Con su aplicación en septiembre de 1731, todo el sistema de subarriendos en las provincias quedará suspendido. Por último, una instrucción real publicada en enero de 1740 organizaba y especificaba las funciones de todos los empleados de la Real Hacienda que entraban en el ejercicio del gobierno de la renta del tabaco.

La política comercial se centrará en obligar al mercado nacional a consumir el producto procedente exclusivamente de las colonias españolas en América, siendo necesariamente manufacturado en Sevilla, cuyas fábricas se potenciarán para ser el único punto oficial de producción de tabaco con destino al mercado de la península, mientras mediante una articulación administrativa se suministraba a la periferia peninsular.

La situación del archipiélago canario cambiaría repentinamente de rumbo con la puesta en marcha del nuevo sistema administrativo. El archipiélago quedó integrado en el monopolio en 1636, pero la cesión de arriendos en 1650 se habia convertido en una enajenación del tráfico tabacalero en favor de particulares. Así aparecieron fórmulas propias para la adquisición del producto, convirtiendo a Canarias en un importante centro de reexportación de tabacos hacia Europa, algo que la hacienda real pretendia erradicar. Esto se tradujo en un cierto rigor con el comercio del tabaco, en el que se pretendia cortar las interferencias de particularismos dentro de la exclusividad que se aspiraba a establecer en la conexión La Habana-Sevilla. La acción real no fue fácil, pues los intereses en juego eran tantos que incluso la situación influyó en la muerte del intendente Ceballos en Santa Cruz Tenerife en 172049. Este asesinato estuvo vinculado a una serie de sucesos relacionados con la creación de la Intendencia en Canarias. Según Manuel Hernández, esta nueva institución creó un conflicto entre aquellos que practicaban el contrabando de tabaco en Canarias y el propio Ceballos, y además puso en duda la autoridad vigente en las islas hasta ese momento.

La creación de la Intendencia de Canarias dañaba el poder absoluto en materia de rentas reales y de hacienda, algo que hasta entonces recaía en los capitanes generales. Su gestión, encaminada al control del tráfico de tabaco y las pertinentes medidas para crear un comercio sometido ante el monopolio estatal, ocasionará notables tensiones en todos los sectores sociales de Tenerife. Además, su gestión chocó con otras jurisdicciones como la del capitán general.

También es importante señalar que desde todos los sectores sociales el intendente encontró resistencia a sus políticas. Los comerciantes se encontraron con una prohibición para comprar y traer tabaco por su cuenta; otros se vieron perjudicados debido a que no podían reexportarlo a Cádiz y a Europa, o cambiarlo por géneros de contrabando. El clero fue otro sector afectado por las nuevas politicas, ya que era bien conocida la actividad contrabandista que realizaban. Incluso el papel de la nobleza en el motín pudo haber sido el de incitador, ya que el dia antes de los acontecimientos muchos se marcharon de

49 Ibid., pp. 51-91.

https://doi.org/10.53335/cliocanarias.2021.3.02

Cliocanarias, ISSN 2695-4494, n. ${ }^{\circ} 3$ (2021), pp. 1-36, La Laguna (Canarias)/ 19 
Santa Cruz a La Laguna, allanando el terreno para el amotinamiento ${ }^{50}$. La chispa del motín terminó de saltar cuando Ceballos se excedió en su jurisdicción, al intentar actuar contra una mujer y un esclavo por su mal amistado.

Juan Antonio Ceballos sería sacado de su casa a rastras y golpeado hasta la muerte. Este hecho fue condenado por las autoridades de la isla, que rápidamente intentaron restar responsabilidad a las instituciones politicas de Tenerife. Debido a ello, el capitán general actuó con contundencia y una serie de individuos fueron ejecutados y expuestos sus cuerpos a modo de escarmiento público; otros fueron desterrados o condenados a galeras. De este modo, la oligarquía concentró el peso del crimen de Ceballos en la clase baja y el Cabildo procuró exonerarse de cualquier tolerancia o pasividad con lo acaecido ${ }^{51}$.

Como veremos en el siguiente subapartado, además de establecerse el monopolio sobre la producción, distribución y venta del tabaco en Cuba, se fundó la primera factoria de La Habana con la función de ser centro comprador en exclusiva e intermediario entre los vegueros y la Real Hacienda. Este hecho tendrá notorias consecuencias en Cuba y en el sistema del estanco del tabaco, proceso que terminaría con la creación de la Compañia de Tabaco de La Habana en $1740^{52}$.

Al modelo de estanco expuesto se le acercaría el de Santo Domingo, Puerto Rico y, con sus particularidades, Venezuela. Mencionemos asimismo el paradigma utilizado en Nueva España, el más exitoso de todos ${ }^{53}$. En lo referente a este virreinato, es importante mencionar el papel que tuvo en la financiación del estanco imperial, pues aportó recursos fiscales netos en una proporción mayor al resto de los demás territorios. Además, financió la compra del centro productor para el estanco metropolitano, la factoria de La Habana ${ }^{54}$

Este fue el camino de erección y establecimiento del estanco y monopolio del tabaco en el reino español, con sus luces y sombras, hasta mediados del siglo XVIII. Sin embargo, para investigadores como Solbes Ferri una de las sombras de este sistema fue orientar la producción en sus inicios al tabaco en polvo, ya que el tabaco en humo se estaba convirtiendo en el predilecto de la sociedad, algo que tuvo que solventar con la compra de tabaco extranjero (tabaco brasileño). Desde la década de 1760 la Corona se vio obligada a adquirir cada vez más cantidad de tabaco de Brasil. A esto podemos sumar la decadencia cada vez mayor del tabaco traído por la Compañia de La Habana, que se pretendió suprimir en 1760 para establecer la factoría nuevamente ${ }^{55}$. Desde la citada década de 1760 se intentó dar un impulso sostenido al monopolio de

\footnotetext{
50 HERNÁNDEZ GONZÁLEZ, M.: "Intrahistoria de una rebelión contra la intendencia: el motín de Ceballos de 1720", en Anuario de Estudios Atlánticos, n. ${ }^{\circ}$ 46, Tenerife, 2000, pp. 319-347. 51 SOLBES FERRI, S.: "Abastecimiento y distribución de tabacos en el marco del estanco general español (siglos XVII y XVIII)", en SANJUANBENITO A.: Tabaco e historia económica. Estudios sobre fiscalidad, consumo y empresa (siglos XVII-XX), Madrid, 2006, pp. 133-148.

52 Ibid., pp. 133-148.

53 Cultivo restringido a determinadas zonas, manufacturas estatales, control de la distribución y, por encima de todo, la recaudación fiscal.

${ }^{54}$ LUXÁN MELÉNDEZ, Santiago de: «El proceso de construcción del estado imperial hispánico 1620-1786. Las reformas borbónicas del siglo XVIII", en Anuario de Estudios Atlánticos, n. ${ }^{\circ}$ 65, 2018, pp. 65-125.

55 SOLBES FERRI, S.: "Abastecimientos y distribución de...", art. cit., pp. 133-148.
} 
tabaco para así convertirlo en una empresa universal56, pero la invasión inglesa de La Habana hizo reconsiderar estas ideas hasta 1767. El régimen de adquisiciones se mantuvo hasta 1783, mientras que el monarca Carlos III paralelamente promulgaba los decretos de libre comercio colonial, suprimiendo así cualquier intento de monopolio ${ }^{57}$.

Para Solbes Ferri la administración directa de la Corona fue un deseo por parte de esta de incrementar, entre otros ámbitos, el control y la organización del abastecimiento del producto. Sin embargo, en la década de 1760 un sucesivo cúmulo de inconvenientes, sumados a las prevalencias de gustos de la sociedad por el tabaco de humo y al constante fraude y contrabando, motivó que la monarquía diera por finalizada la aventura monopolista ${ }^{58}$.

Para concluir, Luxán Meléndez señala la importancia de la articulación que tuvo el estanco en la primera mitad del siglo XVIII con el eje Nueva España (financiación)-Cuba (centro de producción de tabaco)-Sevilla (elaboración y redistribución del producto al estanco metropolitano), así como la extensión del monopolio a los territorios americanos entre 1760-178659.

\subsection{El estanco del tabaco en Cuba. Procesos y consecuencias}

Durante el periodo de administración directa de 1684 a 1687 se definió el proyecto de convertir a Cuba en único centro proveedor de la fábrica sevillana, aunque en estos momentos habia sido decretado que los abastecimientos de esta procedieran también de la Guayana, Puerto Rico, Santo Domingo y Brasil, además de hoja para molturar procedente de Sevilla. Con ello se quería conseguir que el proceso de molturación se realizara en la metrópoli y el cultivo en las colonias exclusivamente (pacto colonial) ${ }^{60}$.

Sin embargo, no fue hasta la real cédula de 12 de abril de 1698 cuando podemos decir que se asentó la fundación del estanco en Cuba, institucionalizándose la renta con este documento compuesto por 16 apartados que regulaban el sistema. A comienzos del siglo XVIII, y pese a las diferentes procedencias del tabaco, Cuba se convirtió en la principal abastecedora del estanco ${ }^{61}$. En los años sucesivos diferentes cédulas ordenaban la compra inmediata a la metrópoli, pero estas adquisiciones solian ser insuficientes y de mala calidad: por una parte, debido a la cesión del asiento a la compañía francesa de Guinea tras la Guerra de Sucesión, algo que inundó el mercado de compradores del país vecinos y contrabandistas extranjeros, negociando directamente con los productos; por otra parte, la molienda de tabaco sin control que se estaba produciendo en La Habana, apareciendo el fraude en el proceso.

56 MARICHAL, C.: "Una empresa transatlántica del siglo XVIII: el monopolio del tabaco en Nueva España, Cuba y España", en ALONSO ÁLVAREZ, Luis, Lina GÁLVEZ MUÑOZ, y Santiago de LUXÁN MELÉNDEZ (eds.): Tabaco e historia económica. Estudios sobre fiscalidad, consumo y empresa (siglos XVII-XX), 2006, pp. 413-432.

57 MARTÍNEZ RUIZ, E., C. MAQUEDA, y E. de DIEGO: «El reinado de Carlos III (1779-1788)", en Atlas histórico de España (tomo II), Madrid, 1999, p. 29.

58 SOLBES FERRI S.: "Abastecimientos y distribución de...", art. cit., pp. 133-148.

59 LUXÁN MELÉNDEZ, S. de: "El proceso de construcción...", art. cit., pp. 65-125.

60 Ibid., pp. 51-91.

${ }^{61}$ En algunos momentos, entre el $60 \%$ y $70 \%$ del tabaco era de procedencia cubana. 
La situación no variaría mucho durante casi las dos primeras décadas del setecientos (coincidiendo con el período de la Guerra de Sucesión), hasta que la nueva orientación en la política tabaquera culminará con la creación de la factoría en 1717. El objetivo fundamental de su creación fue asegurar el suministro constante de la rama para la fábrica de Sevilla. Para llevar a buen puerto esta empresa era necesario el control del cultivo, comprando directamente la hoja a los vegueros mediante un monopolio de compra, así como la reducción de la producción del tabaco en polvo para mejorar la calidad del producto (reduciendo el número de molinos). La idea consistía en sufragar la compra del tabaco mediante pagos procedentes de Nueva España y por los envíos de manufacturas desde la metrópoli. Los comerciantes andaluces que traían los géneros debian competir con la compañia francesa, y posteriormente, tras la Guerra de Sucesión, con la Compañía Inglesa de Asientos de Negros $^{62}$.

Sin embargo, como veremos más adelante, el primer intento de implantación de la factoría resultó ser un fracaso debido a las revueltas vegueras producidas entre los años 1717-1724. A este período le sucedió un intervalo anterior al de la intendencia de Martín Loynaz (1725-1726) y el consecutivo establecimiento del nuevo sistema, en el que aumentaron las cantidades de tabaco aunque se perdiera calidad en el producto. Este sistema estuvo vigente hasta que por real orden de 1 de noviembre de 1735 se decretó que la renta de La Habana pasase al particular José Antonio de Tallapiedra, comerciante gaditano ${ }^{63}$.

Los siguientes acontecimientos en el devenir del estanco del tabaco en Cuba están insertos en el periodo comprendido entre la Guerra de la Oreja (1739-1749) y el comienzo del conflicto de las Trece Colonias. El método previo, por el que la Corona otorgaba el estanco a particulares, concluyó en 1740 mediante la constitución de la Real Compañía de La Habana (real cédula de 18 de diciembre de 1740). Esta institución tendría su sede en La Habana y contaría con un factor principal en el puerto de Cádiz, Sevilla, Veracruz o Florida. La real compañia se encargaría también de la adquisición y transporte de azúcar y cueros; del abastecimiento de géneros a la isla; de la conducción de pertrechos a La Habana para

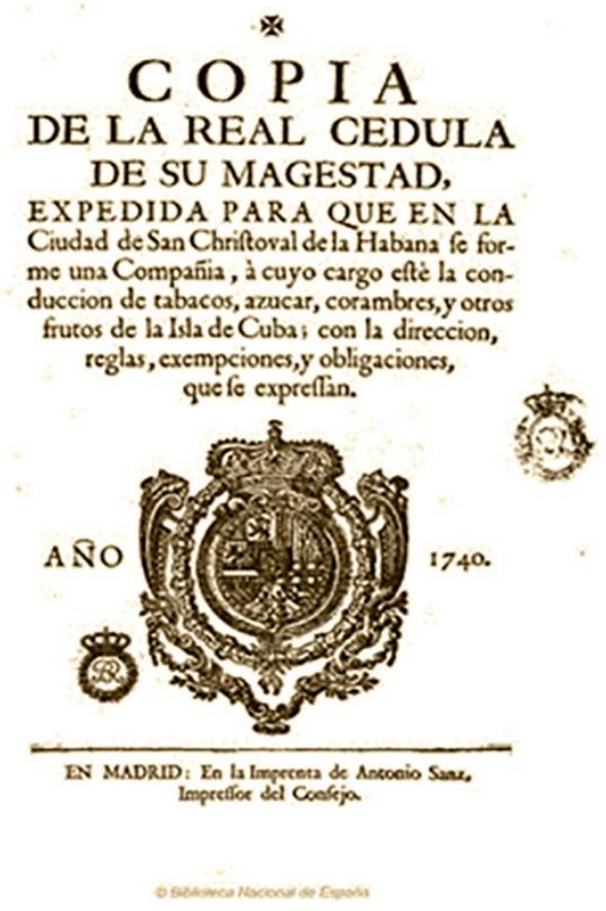

[6] Real cédula de 1740 por la cual se creó la Real Compañia de Comercio de La Habana. Fuente: BNE.

${ }^{62}$ LUXÁN MELÉNDEZ, Santiago de, M. GÁRATE OJANGUREN, y José M. RODRÍGUEZ GORDILLO: Cuba-Canarias-Sevilla. El estanco español..., op. cit., pp. 51-91.

${ }^{63}$ Ibid., pp. 167-243. 
la construcción de barcos; del abastecimiento del presidio de La Florida64; y de la gestión en la lucha contra el contrabando 65 .

Esta compañía retuvo el monopolio (de manera parcial) de compra y venta del tabaco cubano durante veinte años (1740-1761), ya que la Corona resolvió implantar de nuevo la administración directa del monopolio. Este modelo fue impuesto por la Real Hacienda a partir de la década de 1760, simultáneamente en Cuba y la Nueva España66. En el caso de la isla antillana, se restableció mediante la creación de la segunda factoría de La Habana67. Dicho proyecto entró dentro de las reformas de Carlos III, pretendiendo la potenciación del producto para aumentar el tráfico con la metrópoli y con el resto de los territorios de la monarquía borbónica en América. Sin embargo, la puesta en marcha de estos proyectos se truncó debido a la Guerra de los Siete años y a la toma de La Habana por parte los ingleses (1762-1763).

Finalmente, los planes reformadores del monarca borbónico comenzaron a disiparse a partir de la publicación del Reglamento de Libre Comercio de 1778. A la par que esto sucedía, comenzará un declive en la producción y comercialización de tabaco en Cuba que conducirá a la total abolición de la renta en el año $1817^{68}$.

\section{Conflicto entre la factoria y los vegueros. Lucha y violencia en las vegas cubanas}

Pese a la prosperidad del negocio y a la creciente llegada de inmigrantes canarios que buscaban una mejora en su calidad de vida, los campos cubanos fueron el lugar de muchas de las luchas entre campesinos, instituciones y grandes propietarios, en donde entraron en juego privilegios comerciales o tenencia de tierras. En lo referente a la conflictividad, las primeras revueltas sociales con los vegueros como protagonistas acontecieron en 1717, 1720 y 1723 , en las que se enfrentaron a la factoría y fueron conocidas como la sublevación de los vegueros.

Como se señaló en el apartado anterior, el control total del estanco del tabaco pasaría de manos de arrendatarios a la intervención por la administración de las instituciones regias. De este modo, el 3 de mayo de 1684 se promulgó una instrucción que dispuso que el control de la venta del tabaco recaería en manos de la Real Hacienda, hito que fue el antecedente de la creación de la Real Compañía de Comercio de La Habana. Más adelante, exactamente el 11 de abril de 1717, el rey Felipe V decretó el monopolio del tabaco en la isla, lo que originará la primera protesta y posterior revuelta veguera ${ }^{69}$.

\footnotetext{
${ }^{64}$ Importante papel en la emigración canaria, ya que incluía el traslado de familias del archipiélago.

${ }^{65}$ LUXÁN MELÉNDEZ, Santiago de, M. GÁRATE OJANGUREN, y José M. RODRÍGUEZ GORDILLO: Cuba-Canarias-Sevilla. El estanco español..., op. cit., p. 245.

66 MARICHAL, C.: "Una empresa transatlántica del siglo XVIII...", art. cit., p. 10.

${ }^{67}$ LUXÁN MELÉNDEZ, Santiago de, M. GÁRATE OJANGUREN, y José M. RODRÍGUEZ GOR-

DILLO: Cuba-Canarias-Sevilla. El estanco español..., op. cit., p. 245.

68 Ibid.

${ }^{69}$ MARTÍN FRADAGAS, A.: Los canarios y las luchas emancipadoras y sociales en Cuba, Vigo, 2008, pp. 17-20.
} 


\subsection{La primera ruptura: 1717}

En lo que refiere a la creación de la factoría de tabaco, debemos remontarnos a 1716 con la llegada a Cuba del nuevo gobernador, Vicente Raxa. A diferencia de su predecesor Torres Ayala - cuya gestión fue ejemplar debido a sus conocimientos del mercado y la situación de Cuba en general-, la labor de Raxa resultó desafortunada. Su papel engendró conflictividad desde el principio, y como veremos más adelante terminó con su exilio de la isla ${ }^{70}$.

Llegó a Cuba acompañado de cuatro funcionarios que realizaron un estudio sobre la situación del mercado para evaluar los beneficios que se podrian obtener y qué posibilidad real había de establecer la factoría del monopolio. La investigación se basó en la visita a las zonas tabacaleras para examinar la producción, el beneficio comercial y la actitud de los vegueros. Finalmente, el informe resultó positivo, destacando que se podrian alcanzar grandes niveles de producción, lo que hizo que la real instrucción se basara en este dictamen para justificar el estanco.

Los malos presagios de los agricultores se convirtieron en realidad cuando el 27 de julio de 1717 el gobernador Raxa publicó el bando por el cual entró en vigor el estanco del tabaco. Con este bando la Corona pretendia terminar con la salida de tabaco cultivado en su territorio con destino hacia manos extranjeras, algo que ocasionaba pérdidas a las arcas reales. Con el estanco se ordenaba la venta legal del tabaco a la Real Hacienda con un precio establecido previamente. Las ordenanzas intentaron llevar hasta las últimas consecuencias el monopolio y confirman la mentalidad reformista de la dinastía borbónica.

Así pues, el edicto afectó a todo aquel que tenía relación económica con el tabaco. Los más damnificados sin duda fueron los comerciantes, cosecheros y vegueros de tabaco, pero el estanco también alcanzó a otros colectivos indirectamente. Los labradores vieron cómo sus partidas de tabaco eran despreciadas por la administración, no queriéndolas pagar o no alcanzando un precio justo, de modo que resultaba complicado dar salida legal a las cosechas. Ante este escenario, los dueños de molinos y los intermediarios comenzaron a notar que la situación estaba variando notablemente en contra de sus intereses, por lo que empezaron a hacer circular rumores.

Los labradores, que habian expresado sus quejas formalmente ante las autoridades, fueron desoídos. Ante esta situación, convocaron una reunión masiva en Jesús del Monte, población cercana a La Habana. Alrededor de 500 hombres, armados con los machetillos de las labores y algunos con armas de fuego, comenzaron a bloquear el suministro de ganado a La Habana. Posteriormente, avanzaron hacia la ciudad sin encontrar resistencia alguna, contando con el apoyo de numerosos vecinos. Una vez dentro, se dirigieron hacia la plaza de San Francisco para manifestarse frente al Cabildo. El gobernador, desbordado por la situación, decidió encerrarse en la fortaleza de Fuerza Vieja y convocar al Cabildo al dia siguiente.

70 NARANJO RÍO-MIRANDA, J.: "Las revueltas de los vegueros en La Habana (1717-1723)", en Americanía. Revista de Estudios Latinoamericanos, Nueva época, n. ${ }^{\circ}$ 5, 2017, pp. $297-327$. 
Los sublevados hicieron llegar tres peticiones: la salida de La Habana del gobernador y de los funcionarios principales; el perdón general para los amotinados; y que el gobierno quedase en manos de Gómez Maraver, teniente de gobernador. Finalmente, Vicente Raxa se embarcó en uno de los galeones reales y se concedieron las exigencias a los labradores ${ }^{71}$.

La respuesta de la Corte a este evento no se hizo esperar. El 22 de junio de 1718 llegó un nuevo gobernador enviado desde España, el brigadier Gregorio Guazo Calderón. Su primer mandato será enviar a Gómez Maraver a Madrid. Posteriormente, reunió al Cabildo y transmitió la concesión real del perdón general para todos los sublevados. Su siguiente paso fue restablecer la factoría con real cédula de 1718 y crear sedes de esta en Bayamo, Trinidad, Sancti Spíritus y Santiago. También se predispusieron 800.000 pesos para adquirir toda la producción cubana y 200.000 pesos anuales de la Real Hacienda, para así evitar las confrontaciones anteriores ${ }^{72}$.

\subsection{Segunda revuelta veguera: 1720}

Pese a las medidas tomadas para evitar un nuevo conflicto, la actitud de los funcionarios de la factoría - al pagar precios inferiores y demorar los pagosindujo a los cultivadores a protestar ante la máxima autoridad insular. Esto originó un conflicto entre Guazo (con plenos poderes dados por la Corona) y Manuel de León, director de la factoría. Este último enviará una carta desde México ${ }^{73}$ que avivará nuevamente la aversión, ya que en aquella aconsejaba a los grandes cosecheros abonar el tabaco a plazos. El gobernador intentó impedir la circulación de esas noticias debido a que esa decisión era de naturaleza peligrosa, pero su esfuerzo resultó en vano y los vegueros se movilizaron de nuevo.

Entre el 14 y el 27 de junio de 1720 unos doscientos vegueros a caballo incendiaron las cosechas y casas de unos siete vecinos de las localidades de Santiago de las Vegas y Guanabacoa, favorables al pago aplazado. Agrupados en Jesús del Monte, cortaron el agua y la entrada de víveres a La Habana nuevamente. Ante esta situación, el gobernador retuvo a doce de estos vegueros. La intervención del oligarca José Bayona y Chacón y del futuro obispo de Santiago, Pedro Agustín Morell de Santa Cruz, logró convencer a los amotinados para disolver la sublevación. Estos lo aceptaron a cambio de continuar pagando a la factoría al contado y con una exención de 10 pesos del tributo ese año.

Sin embargo, Guazo veía como única solución al problema el escarmiento y la represión a medio plazo, por lo que aumentó en efectivos a la compañía de caballería de 30 a 100 unidades. También expuso al Consejo la necesidad de contar con dinero para realizar los pagos al contado, ya que la única forma de que se acatara el estanco era esa; si no, la fuerza sería el único medio. Frente a esta realidad, la Corona permitió a los labradores dar salida al tabaco que no podía ser comprado por la Real Hacienda, mediante real decreto de 17 de noviembre de 1720. Se consintió el libre comercio con el resto de la América

${ }^{71}$ Ibid., pp. 297-327.

72 Ibid.

${ }^{73}$ Había marchado para controlar los envíos comerciales desde allí. 
española y se volvió a conceder el perdón real a los sublevados, pero la monarquía no estaba dispuesta a ceder y estaba decidida a llevar la total gestión de la comercialización del producto ${ }^{74}$.

\subsection{Tercer y último enfrentamiento: 1723}

Como quedó reflejado anteriormente, lo único que se había conseguido era retrasar el problema, por lo que la tensión volvió a resurgir. Rivero ha explicado la génesis del problema. A principios de 1723, debido a una situación en la que la factoría pudo acometer una serie de pagos en efectivo, los intermediarios vieron cómo mucha mercancía quedaba en stock y no podian dar salida a sus reservas. Entonces hicieron difundir entre los vegueros algunos rumores acerca de que los oficiales reales y los comerciantes estaban conspirando contra ellos, y se esparcían bulos sobre una eventual restauración del estanco.

Debido esta situación, los vegueros comenzaron a aglutinarse en el poblado de San Miguel del Padrón el 20 de febrero de 1723. Empezaron entonces a arrancar las matas de tabaco, repitiendo el mismo proceso en las zonas de Guanabacoa y Jesús del Monte. Tenian igual intención de volver a realizar esta acción en el partido de Santiago de las Vegas y en las nuevas poblaciones de San Felipe y Santiago de Bejucal en caso de que los labradores de esas zonas se resistieran a hacerlo.

Ante la gravedad que presentaba el escenario, el gobernador Guazo Calderón ordenó aplacar la insurrección, enviando a los soldados de caballería contra los amotinados, reprimiendo la rebelión. A pesar de que los planes de los rebeldes acabaron en fracaso, estos continuaron en la lucha con el fin de liberar a los

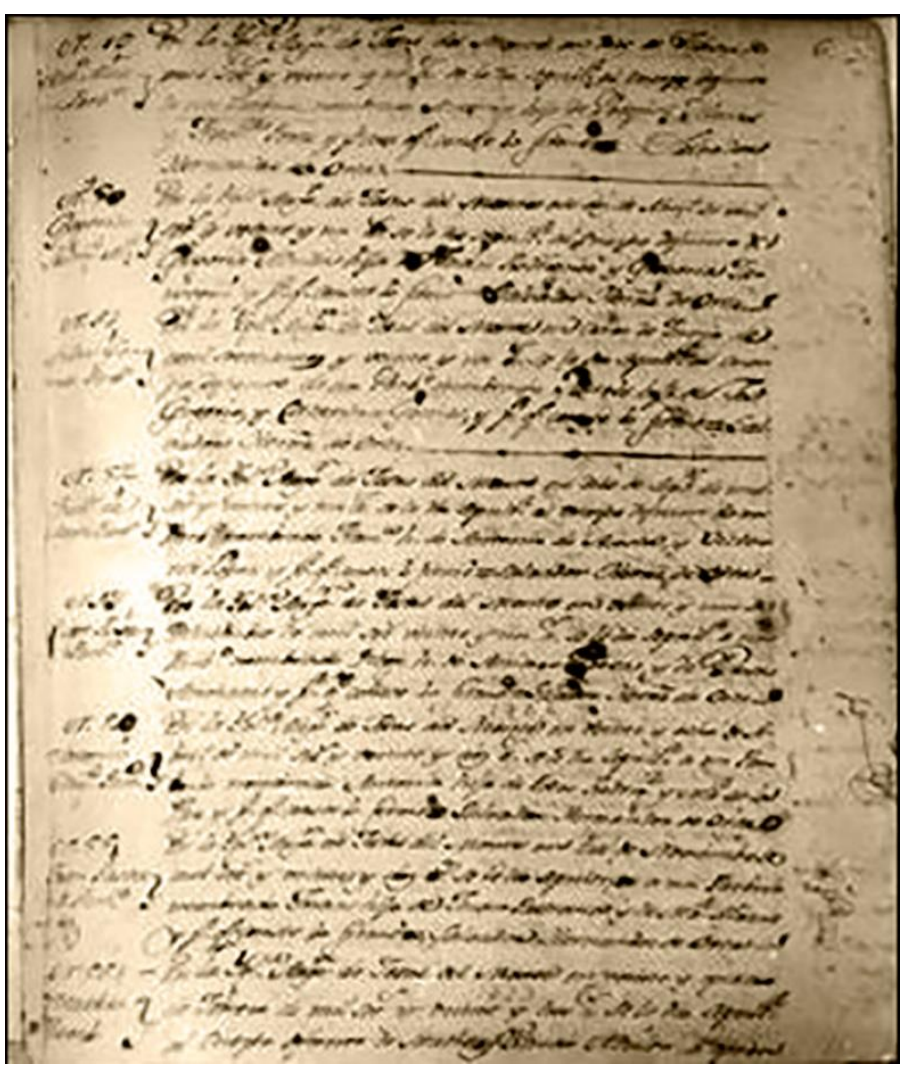

[7] Asientos de entierro de los vegueros en el cementerio de la parroquia de Jesús del Monte. Fuente:

NUMA AGUILA, L: "Los canarios de Jesús del Monte, mitos y realidades", en Monografías.com, La Habana, 2013. prisioneros en la refriega contra la autoridad real, expandiéndose la insurrección a Guanabacoa, Corral Falso

74 HERNÁNDEZ GONZÁLEZ, MANUEL V.: Reformismo borbónico y contestación social: la erección del monopolio de tabaco en La Habana (1717-1723), en Libros de la Corte, número extra 4, 2016, pp. 13-15. 
y San Miguel del Padrón. Debido a esta situación, se ordenó la ejecución inmediata de los vegueros presos, siendo arcabuceados y colgados durante cuarenta horas en los árboles del camino real.

La manera de actuar de las autoridades provocó controversia y malestar entre los diferentes estamentos sociales de la isla, debido al atropello que se cometió contra estos labradores, algo que podría espolear el abandono de zonas donde vivian otros vegueros buscando refugio para ellos y sus familias, lo que redundaría en descuido y abandono de los caminos y su falta de protección ${ }^{75}$.

Las noticias de estas irregularidades llegaron a la Corte, donde se informó sobre la violenta manera de proceder contra los agricultores, ejecutados sin formarse causa y sin poder defenderse. Por ello, el 17 de junio de 1724 el rey dirigió una real cédula al gobernador de La Habana para que permitiese el libre comercio del tabaco cosechado en la isla y el cese de las adquisiciones de la Real Hacienda. Sin embargo, las operaciones continuaron realizándose por los propios funcionarios de la antigua factoria a través de la Intendencia General de Tabaco que se había establecido en La Habana, a la que que entre otras concesiones se le dio el monopolio del tabaco enviado de Cuba a la Peninsula ${ }^{76}$.

En los estudios de Dolores Guerra López encontramos una serie de reflexiones importantes para entender el fenómeno rebelde. Debemos tener como consideración final que este proceso convulso en la historia de los vegueros en Cuba tuvo varias consecuencias. El establecimiento del estanco ocasionó un freno en la industria tabacalera cubana debido a la limitación del incremento de la fabricación de su materia prima. Respecto a la situación de los vegueros, si bien algunos llegaron a la categoría de hacendados, la mayoria siguieron siendo pequeños campesinos o propietarios que disponian de una libertad de grado variable. Las vegas se convirtieron de manera paulatina en parte de grandes propiedades, pasando a ser parcelas arrendables.

La inmigración canaria asumió un papel notorio en esta rebelión, ya que al ser pequeños propietarios se vieron afectados por un proceso en el que grandes comerciantes peninsulares monopolizaron el comercio tabacalero. De ahí el cariz económico de la rebelión, cuya base se gestó en los pequeños agricultores criollos y aquellos provenientes de Canarias. Sin embargo, el motín no tuvo un carácter estrictamente revolucionario, ya que la única intención era acabar con el monopolio. Por tanto, este acontecimiento no puede entenderse como el comienzo de un movimiento independentista que surgiría a la postre, aunque es innegable el sentimiento de rebeldia contra un sistema impuesto que abusaba y atacaba su manera de subsistir.

La mayoría de los canarios y españoles se fusionaron con la estructura social existente en Cuba, algo que explica el posicionamiento de estos descen-

75 GUERRA LÓPEZ, D.: "La sublevación de los vegueros canarios: simiente de la identidad del pueblo cubano", en XIII Coloquios de Historia Canaria-Americana, Gran Canaria, 1998, pp. 2.697-2.700.

76 Ibid. 
dientes durante la lucha de independencia colonial. Fue ese espíritu combativo derivado de la sublevación del siglo XVIII la raíz del sentimiento positivo posterior en Cuba hacia el tabaco y a los cultivadores: los vegueros. Aunque sus tradiciones e identidad en cierto modo se perdieron en el tiempo (durante el siglo XIX muchos abandonaron el campo y pasaron a trabajar en talleres manufactureros), el legado del tabaco quedó vigente en el memorial de lucha e independencia cubana. Como consecuencia, la sedición veguera se puede considerar uno de los primeros antecedentes y simiente de la primera identidad de un pueblo, que se relaciona con la trayectoria de lucha del campesino cubano $^{77}$.

\section{Decadencia del cultivo y comercio tabacalero. El despegue del sistema de plantación}

A finales del siglo XVIII el cultivo del tabaco, motor económico de la isla que se había iniciados en el siglo XVII, comenzó a perder presencia en el panorama económico de Cuba. El fracaso por parte de las instituciones monárquicas de establecer un control fiscal y comercial sobre el producto (monopolio), sumado al avance y empuje que tuvieron otros cultivos, situarán en un segundo plano la explotación tabacalera y la figura del veguero.

Por otra parte, una serie de factores políticos y comerciales (nacionales e internacionales) determinaron un cambio en el planteamiento económico y en la explotación agraria de la isla, consolidándose el sistema de plantación. Estas transformaciones estimularán el paulatino declive del veguero, pasando de ser el referente en el medio rural cubano a convertirse (salvo con excepciones) en parte de la memoria e ideal del campesino cubano.

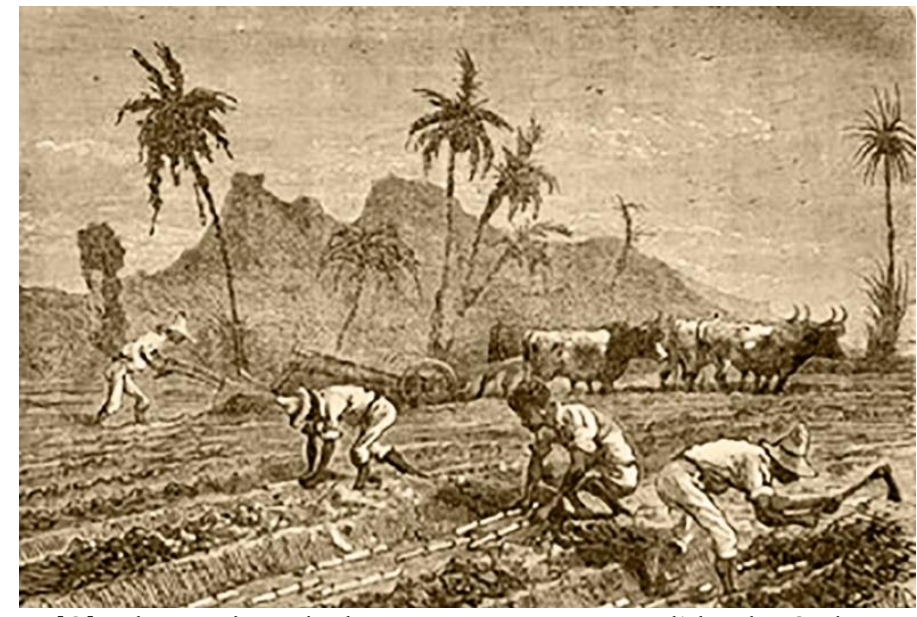

[8] Plantation de la canne à sucre, à l'île de Cuba. Fuente: Flickr, Fondo antiguo de la biblioteca de la Universidad de Sevilla.

\subsection{El progresivo retroceso del cultivo y comercio del tabaco en Cuba}

A partir de la segunda mitad del siglo XVIII el cultivo del tabaco entrará en una fase de retroceso debido a una serie de factores y circunstancias históricas. Fue un proceso iniciado con dificultades en el acceso a tierras de cultivo y un período de menor rentabilidad del producto tabaquero. Los trabajos de Isidro Martín Gutiérrez y Ramón Pérez Linares nos hablan de que la liberación

77 GUERRA LÓPEZ, D.: "Participación de inmigrantes canarios en la sedición de los vegueros en el siglo XVIII", en Tebeto, n. ${ }^{\circ} 13$ (2000), pp. 60-61. 
en 1789 de la trata de esclavos y la rebelión haitiana serán elementos favorecedores del auge de nuevos ciclos económicos en la isla (sistema de plantación) ${ }^{78}$.

Aunque en este período el número de vegueros seguirá en aumento entre 1783 y 1791, el panorama productor cambió radicalmente. Muchos de los que se dedicaban al cultivo en tierras de censo y por arrendamiento se vieron obligados a dejarlas, dirigiéndose a Pinar del Río, centro tabaquero del momento. Las consecuencias del alza de azúcar se tradujeron en un alejamiento de los vegueros de las zonas tradicionales. Estas pasaron a formar parte de las plantaciones, lo que en muchas ocasiones provocó, como en Güines y San Antonio de los Baños, el choque entre hacendados y cultivadores. Una gran parte de los cultivadores fueron expulsados de sus tierras para ser reemplazados por mano de obra esclava en las nuevas plantaciones. Con este panorama, la vega dejó de ser una alternativa rentable y el inmigrante isleño desarrolló sus perspectivas lejos de esta ${ }^{79}$.

Comenzaron entonces estos labradores a desplegar otras estrategias de trabajo relacionadas con aquellas actividades que tenian que ver con el ascendente sistema de plantación, convirtiéndose en mayorales o técnicos. También comenzaron a explotar el pequeño cultivo de abastecimiento y distribución interna dentro de un mercado en expansión que requería de una mayor demanda de productos de primera necesidad.

Pero, sobre todo, el mayor de los problemas que encontraron los trabajadores de las vegas fue la propia rentabilidad del producto del tabaco a finales del setecientos. Esta contrariedad principió durante el periodo de la Compañía de La Habana, pasando esta labor a la factoria nuevamente instaurada. En 1760 se le prohibió a la compañia toda intervención en la cosecha y remisión de tabaco debido a causas de corrupción y fraude. Más adelante, entró en una crisis ocasionada por las pérdidas derivadas de la toma de La Habana por los ingleses (1762). Será el comienzo de la decadencia tabacalera.

En primer lugar, podemos recurrir al estudio realizado por José Luis Belmonte Postigo ${ }^{80}$. En él se indica el inicio de un ciclo en el que el valor del producto cayó, arrastrando a la baja el precio satisfecho al veguero, situación que ofrecía pocas salidas al cultivador. Por dicha razón los labradores comenzaron a acudir a las haciendas azucareras o cafetaleras. Como se reseñó anteriormente, otro de los factores era la problemática de la tierra, ya que los precios de arrendamientos de las tierras cada vez eran mayores, incidiendo en la situación económica de los vegueros. A esto se le unió la escasez de mano de obra en los cultivos, sobre todo de mano de obra esclava, lo que repercutió en la rentabilidad. Por último, si bien existieron dificultades estructurales en el estanco y el monopolio del tabaco que no fomentaban el cultivo, también

\footnotetext{
78 MARTÍN GUTIÉRREZ, I., y R. PÉREZ LINARES: Tabaco e inmigración canaria en la región central de Cuba. El caso de la provincia de Santa Clara, Editorial Académica Española, 2012, pp. 6-10.

${ }_{79}$ Ibid.

80 BELMONTE POSTIGO, JOSÉ L.: "Una crisis de largo recorrido. La decadencia del cultivo del tabaco en el oriente de Cuba a fines del siglo XVIII", en Memorias: revista digital de historia y arqueología desde El Caribe, n. ${ }^{\circ} 11$ (2010), pp. 77-94.
} 
aparecieron ciertas irregularidades de los operarios y veedores a la hora de calificar los productos y darles valor, algo que hacia que los vegueros no recibieran un precio justo por sus productos.

Paralelamente, durante la última década del siglo XVIII una serie de temporales asoló parte de las cosechas cubanas. Añádase el ambiente beligerante en el Caribe con la revolución haitiana y las guerras contra Francia, en cuanto las movilizaciones de vegueros para las milicias abocaron al abandono de algunas zonas de cultivo: el estado de reclutamiento casi permanente en la isla se tradujo en un descenso de las $\operatorname{cosechas}^{81}$.

Hubo un intento de mejorar la situación por parte de las autoridades monopolistas, basado en la mayor eficiencia y en una progresiva liberalización de la producción y distribución del producto. Pero el panorama económico y político internacional, unido a los primeros movimientos emancipadores de comienzos de siglo condenaron al estanco, suprimiendo la corona en 1817 el monopolio sobre la producción y distribución del tabaco ${ }^{82}$.

\subsection{Expansión del sistema de plantación. El azúcar y el café}

Frente al retroceso que estaba sufriendo el cultivo y comercio de tabaco en Cuba, asistimos a finales del siglo XVIII y comienzos del s. XIX a un nuevo sistema de cultivo basado en la explotación de grandes superficies agrarias: el denominado sistema de plantación. En él cobrará un gran protagonismo la plantación y comercialización de azúcar y café83. Para Óscar Loyola Vega teóricamente se trata de un subsistema del sistema capitalista mundial en su etapa mercantil-manufacturera, fundamentalmente caracterizado por la producción de materias tropicales para el mercado mundial, sujeto a sus fluctuaciones $^{84}$.

Todo este fenómeno sucedió a la par que la oligarquía habanera comenzó a acumular capital (lentamente y de forma constante), permitiendo la inversión en trapiches e ingenios. A ello se sumó el advenimiento de nuevas concepciones reformistas liberalizadoras del comercio ${ }^{85}$, combinado con el aumento en Europa de hábitos de consumo de café y azúcar86.

En el caso de la plantación de azúcar conocida como ingenio y trabajada por mano de obra esclava la mayoría de ellas, se constituyó como el sistema socioeconómico primario de Cuba y el motor principal de la economía de la isla durante el siglo $\mathrm{XIX}^{87}$.

81 Ibid.

82 BELMONTE POSTIGO, JOSÉ L.: "Una crisis de largo recorrido...", art. cit., pp. 77-94.

83 El café se desarrollará durante principios del s. XIX, aunque no con las dimensiones que alcanzó el azúcar.

84 LOYOLA VEGA, Ó.: "La sociedad insular", en Cuba y su Historia, La Habana, 2005, pp. 3042.

85 Tratado de libre comercio (1778); libre introducción de esclavos en Cuba (1789).

86 LOYOLA VEGA, Ó.: "La sociedad insular»..., art. cit., pp. 30-42.

87 SANTAMARÍA GARCÍA, A.: "Sugar Plantations". en MARTÍNEZ FERNÁNDEZ, L. et al.: Encyclopedia of Cuba: People, history, culture, vol. 2. ${ }^{\circ}$, Nueva York, 2003, p. 3. 


\section{Noticias de los barcos que han entredo en el Puerto ds no3 of Santa Cruzt. nobsM aroñs 20}

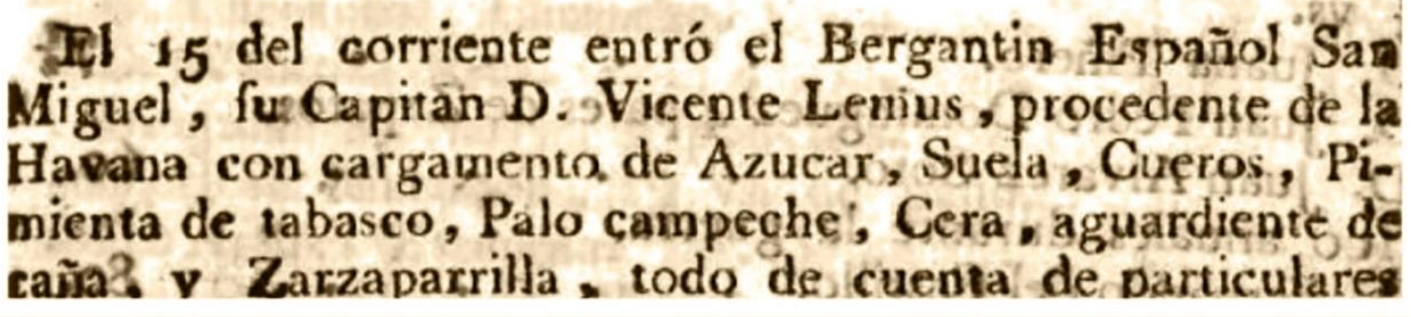

[9] Recorte de prensa: Buque español procedente de la Habana. Entre su cargamento encontramos productos relacionados con la caña de azúcar. BAZZANTI, M. Á. (impresor de la Junta Suprema): "Noticias de los barcos que han entrado en el puerto de Santa Cruz", en El Correo de Tenerife, La Laguna, 19 de enero de 1809, p. 8. Fuente: BULL, Prensa canaria digitalizada.

El especialista sobre la materia Antonio Santamaría García defiende que una serie de factores a finales del siglo XVIII y principios del s. XIX hicieron que Cuba se encaminara a convertirse en el primer exportador mundial de azúcar88: a) la ocupación británica de La Habana (1762) abrió rutas comerciales y estimuló la trata de esclavos en la isla; b) la independencia de las antiguas trece colonias de Norteamérica terminó con las exportaciones británicas a los nuevos Estados Unidos; c) la revolución en Santo Domingo (Haití) destruyó la capacidad de producción del que había sido mayor exportador de azúcar del mundo y exilió en Cuba a un gran número de plantadores junto con su capital; d) además, España contribuyó al auge del azúcar al liberalizar el comercio de esclavos a cambio de un nuevo sistema impositivo, promoviendo la inmigración y facilitando la importación de capital extranjero, maquinaria y técnicos; e) y por supuesto, la apertura del mercado de tierras de la isla, donde el avance de los cultivos comerciales fue eliminando el anterior sistema de hacienda, sobre todo al oeste de Cuba y en torno a los principales puertos. Lo característico del último tercio del siglo XVIII fue un aumento del número de fincas en esas zonas y un proceso de arrendamiento y medianería que permitió aprovechar el suelo, proporcionando capital a los grandes propietarios para modernizar sus explotaciones ${ }^{89}$.

Tales circunstancias favorecieron la integración de las facetas agrarias e industriales para la producción, la incorporación de la tecnología moderna y las técnicas que estaban comenzando a emerger relacionadas con la organización y el comercio. Todo esto sucedia mientras el sistema se sostuvo gracias al trabajo esclavo. A principios del siglo XIX, los ingenios primitivos de azúcar se transformaron en ingenios mecanizados, incorporando progresivamente la potencia del vapor y otros avances tecnológicos. Los resultados serán obvios,

88 SANTAMARÍA GARCÍA, A.: "Azúcar, economía y reformas coloniales. Puerto Rico y Cuba, 1765-1840", en XVI Coloquio de Historia Canario-Americana, Gran Canaria, 2004, pp. 1.6261.627.

89 Ibid. 
ya que en 1760-1764 la isla exportaba una media de 5.300 toneladas de azúcar al año; entre 1810-1814 la cifra se elevó a unas 35.430 toneladas $^{90}$.

Este es el panorama de Cuba a finales del setecientos y comienzos de la centuria decimonónica. Observamos cómo el motor económico de la isla cambió radicalmente, y con él, el comercio, la propiedad de la tierra y la orientación de las relaciones y el trabajo de la sociedad. Si algo notable puede diferenciarse respeto a lo que hasta entonces se había desarrollado en la isla, es la novedad en su fuerza laboral. La esclavitud proveniente de África, que estuvo relacionada con las nuevas explotaciones agrarias, provocó el crecimiento de enormes fortunas en España y Cuba. Pero trajo consigo un régimen de trabajo atroz, pues en la plantación la esperanza de vida fue corta, factor que exigía de manera continua la llegada de más esclavos a esas explotaciones. Además, surgió una fuerte polarización en la sociedad cubana, siendo el esclavo el eslabón más bajo de la cadena y el terrateniente el más alto.

Aunque la plantación fue un próspero régimen económico en Cuba debemos tener en cuenta que su desarrollo no ocupó la totalidad de la isla, sino que se desarrolló en la zona occidental. Todo este mundo de la plantación empezaría a sufrir una serie de recesiones debido a la competitividad del mercado mundial del azúcar ${ }^{91}$. Los burgueses esclavistas intentaron modernizar el sistema para hacerlo más eficaz, pero el propio sistema estaba abocado al fracaso debido a la escasa formación tecnológica del esclavo durante la Revolución Industrial, y tampoco existía suficiente mano de obra asalariada para impulsar el trabajo libre. A todo esto, la demanda de la materia prima (caña de azúcar) por parte de los norteamericanos también afectó a la limitación del desarrollo industrial cubano. Finalmente, el sistema de plantación vería llegar su fin debido a la desaparición de la trata de esclavos en la isla, gracias a la derogación de esta en $1886^{92}$.

\section{Conclusiones}

A lo largo de esta exposición hemos observado el devenir histórico de los vegueros canarios en Cuba durante el transcurso de la Edad Moderna (especialmente durante el siglo XVIII), analizándose el proceso por el cual los "isleños" se asentaron en dicha isla. También se ha comprobado cómo desarrollaron su modo de vida dentro del sistema de la explotación tabacalera cubana, y ligado a esto último pudimos verificar y hallar explicación a las interacciones que mantuvieron con las autoridades reales y comerciales, manteniendo especial atención a los conflictos acaecidos por las luchas de intereses entre las administraciones reguladoras de producción y comercio tabacalero y los propios cultivadores de tabaco. Finalmente, se comentó la recesión en el sistema de explotación tabacalero y el despegue de otros tipos de cultivo en la isla.

Todo esto ha sido el proceso que creó la imagen del veguero en Cuba. Dichos acontecimientos fueron de gran importancia para la historia de la isla antillana, ya que han sido claves en el desarrollo del comercio, de la política y

90 SANTAMARÍA GARCÍA, A.: "Sugar Plantations», art. cit., 2003, p. 3.

91 Ibid.

92 LOYOLA VEGA, Ó: "La sociedad insular»..., art. cit., pp. 30-42. 
de la vida social en la isla. Por eso conviene reflexionar acerca de algunas conclusiones en los siguientes párrafos.

En primer lugar, las primeras arribadas de contingentes europeos a Cuba estuvieron marcadas por la idea de colonización y explotación de los territorios descubiertos. No fue hasta el siglo XVII cuando una serie de factores propios de esa isla (exterminio indio y falta de colonos) impulsó la llegada de las primeras oleadas de emigración canaria, gracias en parte a las políticas de poblamiento de la Corona. Mas será durante el siglo XVIII cuando se experimente un proceso de emigración canario - aún mayor si cabe-debido a causas relacionadas con el auge tabacalero Cuba, las redes migratorias entre Canarias y Cuba, así como a un período de crisis en el archipiélago canario que multiplicó la salida de muchos isleños con destino a América.

En segundo lugar, la llegada de los canarios a Cuba trajo consigo la fundación de nuevos núcleos que ayudaron a colonizar territorio que estaba en pleno decrecimiento poblacional, aunque es cierto que en determinados casos el proceso de creación de algunos pueblos estuvo marcado por disputas entre la clase dominante y aquellos campesinos que pretendian optar a tierras propias para la explotación del tabaco. Fue en estos lugares donde el sistema de explotación favoreció la modelación de la figura del veguero, el cual llevó a cabo la explotación de la planta de tabaco basado en un modelo de arrendamiento unifamiliar de campesinos blancos. Con ellos se asentó en Cuba la cultura que trajeron desde Canarias muchos inmigrantes: sus conocimientos para cultivar, sus creencias y su sabiduria popular.

En tercer lugar, otra de las consecuencias que tuvo el cultivo del tabaco de la isla fue el gran rendimiento económico que la Corona sacó de este producto. Sin embargo, a la hora de su administración la monarquía llevó a cabo una regulación del sistema que primeramente fiscalizó el estanco del tabaco, con irregulares resultados. Pronto intentó optar por el total control del sistema desde su producción, pasando por su manufactura y comercio. Este proceso no llegó a buen puerto, debido a la resistencia por parte de los vegueros al monopolio de la producción y negocio tabacalero. Existian muchos factores negativos para los vegueros e intermediarios si este sistema conseguía asentarse, ya que los labradores recibirian una remuneración menor con la implantación de la factoría que con la libre venta; y de igual forma, los intermediarios veían peligrar sus existencias almacenadas y sus especulaciones dentro del mercado. Todo esto, asociado a otros factores mercantiles, desembocó durante el tercer cuarto del siglo XVIII en la declaración de libre comercio en los puertos españoles y sus colonias.

Finalmente, una serie de factores internacionales desencadenará un cambio radical en del sistema económico de la isla. El tabaco dará paso al despegue del sistema de plantación. La revolución de Haití y el comercio con las Trece Colonias convertirá a Cuba en el epicentro de la producción de azúcar dentro del Caribe. Este despegue se verá favorecido por la permisión de la trata de esclavos en la isla para el trabajo forzado en el cultivo. La gran plantación se impondrá al tradicional cultivo de tabaco, que experimentó un retroceso debido a la falta de tierras y a la caída de precios del tabaco, todo suma- 
do a las mejores expectativas que ofrecian la plantación azucarera y, en cierto momento, el cafetal.

Estas circunstancias fueron las que tuvieron que afrontar aquellos emigrantes canarios que durante el siglo XVIII surcaron el mar en busca de un futuro próspero y mejores oportunidades en una tierra que estaba semihabitada y que comenzaba a ensayar un desarrollo agrícola que giraba en torno al tabaco. Fueron estos emigrantes los que se asentaron en las tierras que lindaban con los ríos de las vegas cubanas, echando raíces y creando lazos sociales con sus vecinos cubanos, tendiendo así puentes que atravesaban el océano Atlántico.

En definitiva, el veguero isleño representa el prototipo del canario que a lo largo de la historia, por uno u otro motivo, tuvo que abandonar su tierra en busca de la prosperidad y la oportunidad que no le daba su lugar de origen. Y con él una parte de Canarias se iba, arraigándose en los territorios donde pretendía mejorar su situación y la de sus seres queridos. Esos lugares de destino de algún modo pasan a formar parte de la historia de Canarias, de su cultura, pareciendo a veces una prolongación del archipiélago.

\section{Bibliografia}

BELMONTE POSTIGO, J. L.: "Una crisis de largo recorrido. La decadencia del cultivo del tabaco en el oriente de Cuba a fines del siglo XVIII", en Memorias: revista digital de historia y arqueología desde El Caribe, n. ${ }^{\circ} 11$ (2010).

BERGASA PERDOMO, O.: "La fiscalidad sobre el tabaco", en SOLBES FERRI, Sergio, Juan José LAFORET HERNÁNDEZ, y Santiago de LUXÁN MELÉNDEZ: El mercado del tabaco en España durante el siglo XVIII: fiscalidad $y$ con-sumo, Gran Canaria, 2000.

BRUQUETAS DE CASTRO, F.: "La emigración canaria a Cuba y El Caribe. Aspectos cualitativos", en XXIII Coloquio de Historia Canario-Americana, Casa de Colón, Cabildo de Gran Canaria, 2020.

CRUZ HERNÁNDEZ, JOSÉ L.: "Proceso migratorio de la Villa de Mazo e inserción en la cultura del trabajo tabacalero cubano", en TUDELA GALVÁN, A.: Canarios en Cuba. Una mirada desde la antropología, Gobierno de Canarias, Cabildo de Tenerife, Santa Cruz de Tenerife, 1996.

GUANCHE, J.: "Aportes canarios a la cultura campesina cubana", en Revista de la Biblioteca Nacional José Martí, 3. ${ }^{a}$ serie, $n^{\circ}$ 26, La Habana, 1985.

GUERRA LÓPEZ, D.: "La sublevación de los vegueros canarios: simiente de la identidad del pueblo cubano". en XIII Coloquio de Historia Canario-Americana, Casa de Colón, Cabildo de Gran Canaria, Gran Canaria, 1998.

- "Participación de inmigrantes canarios en la sedición de los vegueros en el siglo XVIII", en Tebeto, n. ${ }^{\circ} 13$ (2000). 
HERNÁNDEZ GONZÁLEZ, M.: "La influencia cultural de Canarias en las Antillas hispanas: la penetración de los hábitos socio-culturales del campesinado isleño en la población negra de Cuba", en Anuario de Estudios Atlánticos, n. ${ }^{\circ} 38$ (1992).

- La emigración canaria a américa (1765 - 1824), Ayto. de la Laguna; Ayto. de Icod de los Vinos; Centro de la Cultura Popular Canaria, Tenerife, 1996.

- "Intrahistoria de una rebelión contra la intendencia: el motín de Ceballos de 1720", en Anuario de Estudios Atlánticos, n. 46 (2000).

- "La emigración canaria a América a través de la historia", en Cuadernos Americanos, Tenerife, 2008.

— "Reformismo borbónico y contestación social: "La erección del monopolio de tabaco en La Habana (1717-1723)", en Libros de la Corte, número extra 4, 2016.

HUSSEY, R. D.: Reseña de la obra de José RIVERO MUÑIZ: Las tres sediciones de los vegueros en el siglo XVIII, La Habana, 1951, en The Hispanic American Historical Review, vol. 33, n. ${ }^{\circ} 2$ (1953).

JUÁREZ MARTÍNEZ, A., y G. SÁNCHEZ ÁLVAREZ: "La Candelaria: herencia cultural de Canarias en la ruta de la mar atlántica: España-Cuba-México", en XXII Coloquio de Historia Canario-Americana, Casa de Colón, Cabildo de Gran Canaria, Gran Canaria, 2017.

LOYOLA VEGA, Ó.: "La sociedad insular", en LÓPEZ CIVERIO, Francisca, Óscar LOYOLA VEGA y Arnaldo SILVA LEÓN: Cuba y su Historia, Gente Nueva, La Habana, 2005.

LUXÁN MELÉNDEZ, S.: "El proceso de construcción del estado imperial hispánico 1620-1786. Las reformas borbónicas del siglo XVIII", en Anuario de Estudios Atlánticos, $n^{\circ}$ 65, Casa de Colón, Cabildo de Gran Canaria, Gran Canaria, 2018.

LUXÁN MELÉNDEZ, S., M. GÁRATE OJANGUREN, y José M. RODRÍGUEZ GORDILLO: Cuba-Canarias-Sevilla. El estanco español del tabaco y las Antillas (1717-1817), Cabildo de Gran Canaria, Gran Canaria, 2012.

MARICHAL, C.: "Una empresa transatlántica del siglo XVIII: el monopolio del tabaco en Nueva España, Cuba y España", en ALONSO ÁLVAREZ, Luis; Lina GÁLVEZ MUÑOZ; y Santiago de LUXÁN MELÉNDEZ (eds.): Tabaco e historia económica. Estudios sobre fiscalidad, consumo y empresa (siglos XVII-XX), 2006.

MARRERO, L.: Cuba: economia y sociedad, tomo IX, La Habana, 1976. MARTÍN FRADAGAS, A.: Los canarios y las luchas emancipadoras y sociales en Cuba, Grupo de comunicación Galicia en el Mundo, Vigo, 2008.

MARTÍN FRADAGAS, A.: Los canarios y las luchas emancipadoras y sociales en Cuba, Grupo de comunicación Galicia en el Mundo, Vigo, 2008.

MARTÍN GUTIÉRREZ, I., y R. PÉREZ LINARES: Tabaco e inmigración canaria en la región central de Cuba. El caso de la provincia de Santa Clara, Editorial Académica Española, 2012.

MARTÍNEZ RUIZ, E.; C. MAQUEDA, y E. DE DIEGO: "El reinado de Carlos III (1779-1788)", en Atlas histórico de España, t. II, Ediciones AKAL, Madrid, 1999. 
NARANJO RÍO-MIRANDA, J.: "Las revueltas de los vegueros en La Habana (1717-1723)", en Americanía. Revista de Estudios Latinoamericanos, n. ${ }^{\circ} 5$, Nueva Época, Sevilla, 2017.

PAZ SÁNCHEZ, M. de: La imagen de sí mismos. Los isleños en la revista Islas Canarias de La Habana", en Studia histórica. Historia Contemporánea, n. ${ }^{\circ}$ 15 (1997).

PAZ SÁNCHEZ, M. de, y M. HERNÁNDEZ GONZÁLEZ: La América Española (1763-1898). Cultura y vida cotidiana, Madrid, 2000.

RODRÍGUEZ MENDOZA, F.: La emigración del noroeste de Tenerife a América durante 1750-1830, (tesis doctoral), Universidad de La Laguna, Tenerife, 2004.

SANTAMARÍA GARCÍA, A.: "Azúcar, economía y reformas coloniales. Puerto Rico y Cuba, 1765-1840", en XVI Coloquio de Historia Canario-Americana, Casa de Colón, Cabildo de Gran Canaria, Gran Canaria, 2004.

- "Sugar Plantations", en MARTÍNEZ FERNÁNDEZ, L., et al.: Encyclopedia of Cuba: People, history, culture, vol. 2. ${ }^{\circ}$, Greenwood Press, New York, 2003.

SOLBES FERRI, S.: "Abastecimientos y distribución de tabacos en el marco del estanco general español (siglos XVII y XVIII)", en SANJUANBENITO A.: Tabaco e historia económica. Estudios sobre fiscalidad, consumo y empresa (siglos XVII-XX), Altadis, Madrid, 2006.

TORNERO TINAJERO, P.: "Inmigrantes canarios en Cuba y cultivo tabacalero. La fundación de Santiago de las Vegas (1745-1771)", en IV Coloquio de Historia Canario-Americana, Casa de Colón; Cabildo de Gran Canaria, Gran Canaria, 1980. 